\title{
Report on FY17 Testing in Support of Integrated EPP-SMT Design Methods Development
}

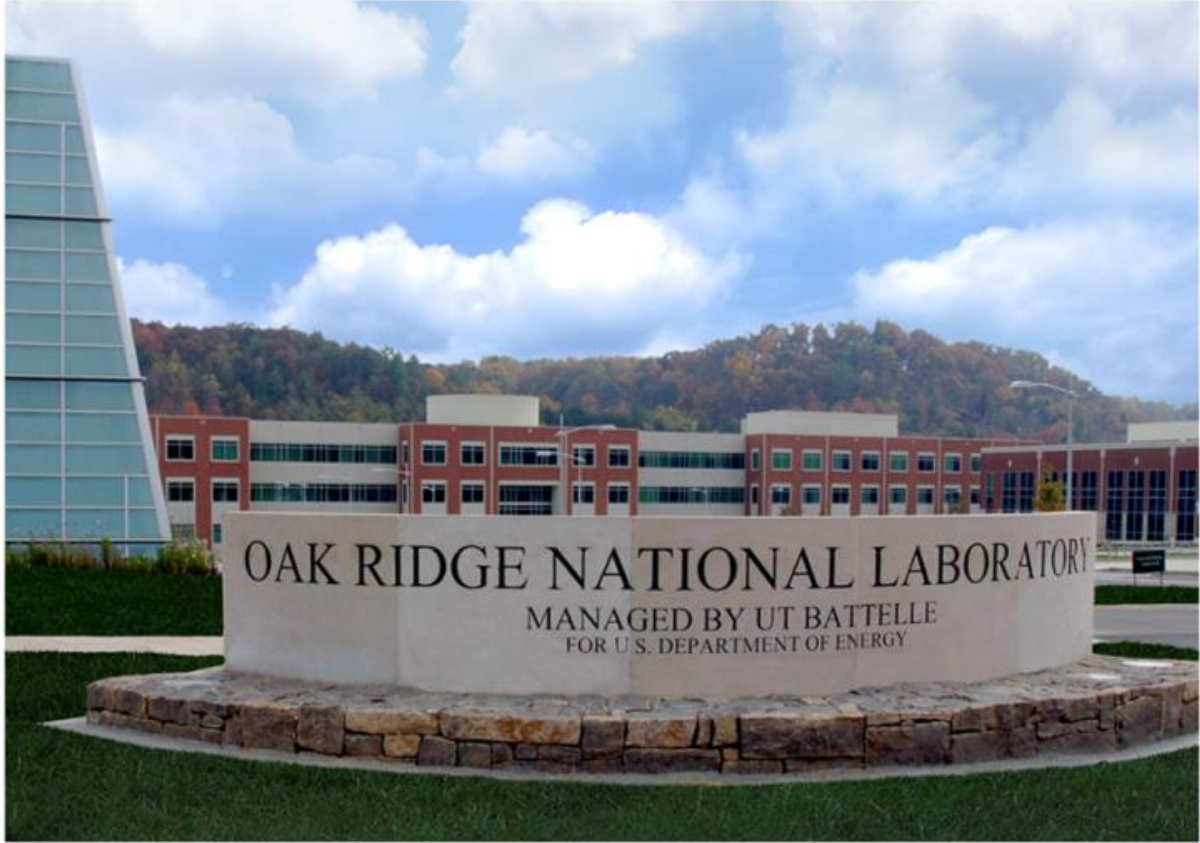

\section{Approved for public release.} Distribution is unlimited.

Yanli Wang

Robert I. Jetter

T.-L. Sham

August 1, 2017 


\title{
DOCUMENT AVAILABILITY
}

Reports produced after January 1, 1996, are generally available free via US Department of Energy (DOE) SciTech Connect.

Website http://www.osti.gov/scitech/

Reports produced before January 1, 1996, may be purchased by members of the public from the following source:

\author{
National Technical Information Service \\ 5285 Port Royal Road \\ Springfield, VA 22161 \\ Telephone 703-605-6000 (1-800-553-6847) \\ TDD 703-487-4639 \\ Fax 703-605-6900 \\ E-mailinfo@ntis.gov \\ Website http://www.ntis.gov/help/ordermethods.aspx
}

Reports are available to DOE employees, DOE contractors, Energy Technology Data Exchange representatives, and International Nuclear Information System representatives from the following source:

Office of Scientific and Technical Information

PO Box 62

Oak Ridge, TN 37831

Telephone 865-576-8401

Fax 865-576-5728

E-mail reports@osti.gov

Website http://www.osti.gov/contact.html

This report was prepared as an account of work sponsored by an agency of the United States Government. Neither the United States Government nor any agency thereof, nor any of their employees, makes any warranty, express or implied, or assumes any legal liability or responsibility for the accuracy, completeness, or usefulness of any information, apparatus, product, or process disclosed, or represents that its use would not infringe privately owned rights. Reference herein to any specific commercial product, process, or service by trade name, trademark, manufacturer, or otherwise, does not necessarily constitute or imply its endorsement, recommendation, or favoring by the United States Government or any agency thereof. The views and opinions of authors expressed herein do not necessarily state or reflect those of the United States Government or any agency thereof. 
Materials Science and Technology Division

\title{
REPORT ON FY17 TESTING IN SUPPORT OF INTEGRATED EPP-SMT DESIGN METHODS DEVELOPMENT
}

\author{
Yanli Wang, Robert I. Jetter* and T.-L. Sham† \\ * RI Jetter Consulting \\ $\uparrow$ Argonne National Laboratory
}

Date Published: August 1, 2017

\author{
Prepared by \\ OAK RIDGE NATIONAL LABORATORY \\ Oak Ridge, TN 37831-6283 \\ managed by \\ UT-BATTELLE, LLC \\ for the \\ US DEPARTMENT OF ENERGY \\ under contract DE-AC05-00OR22725
}





\section{CONTENTS}

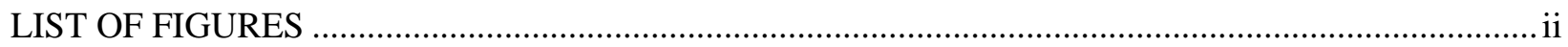

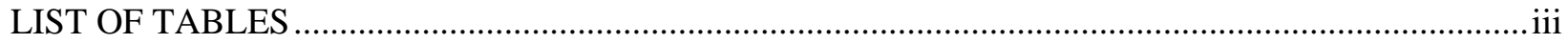

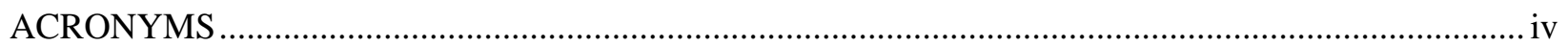

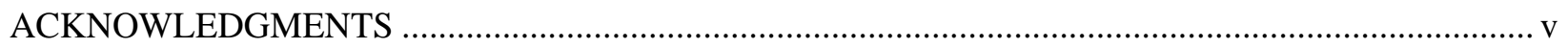

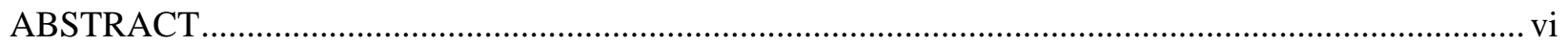

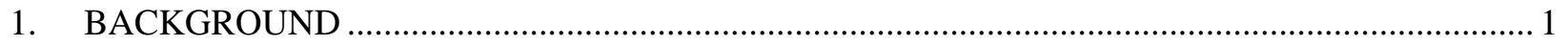

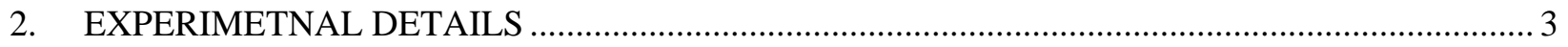

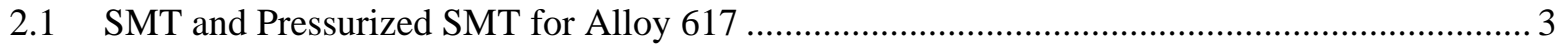

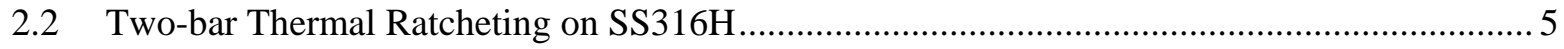

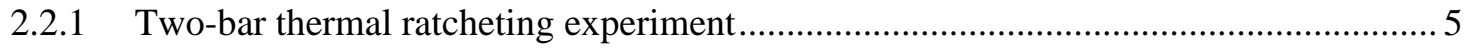

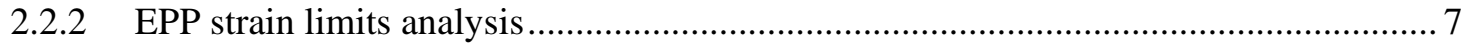

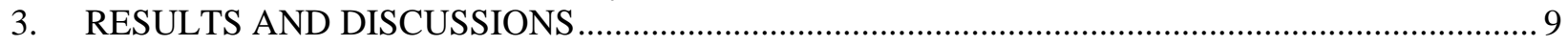

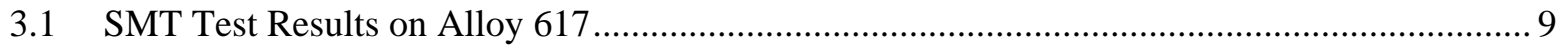

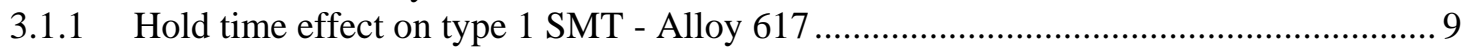

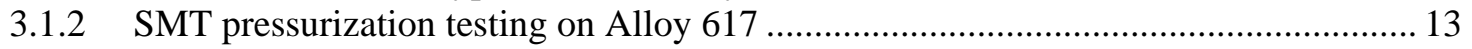

3.2 Two-bar Thermal Racheting Experimental and Analytical Results on SS316H ................... 17

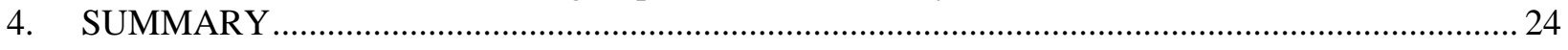

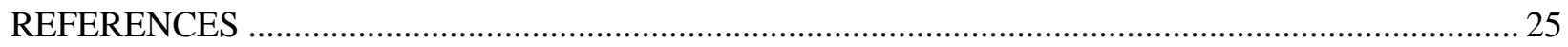




\section{LIST OF FIGURES}

Fig. 1. Updated flow-chart on the development of the EPP-SMT approach. ........................................... 1

Fig. 2. Type 1 SMT solid bar specimen geometry for Alloy 617. Units are in inches. .............................. 3

Fig. 3. Center test section of the pressurization SMT specimen for Alloy 617. Units are in inches. ........... 4

Fig. 4. Applied end-displacement profile for one cycle of SMT creep-fatigue testing with tension hold (a) and combined tensile-compression hold (b).

Fig. 5. Specimen geometry the SS316H used in two-bar thermal ratcheting experiments. Units are in inches.

Fig. 6. Pressurized cylinder with radial thermal gradient represented by a two-bar model....................... 6

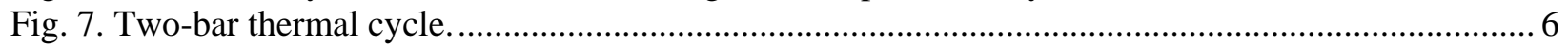

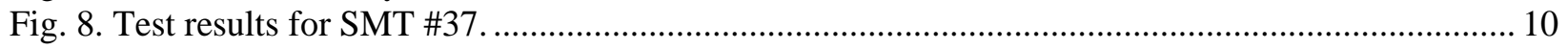

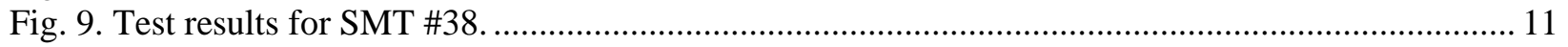

Fig. 10. Effect of hold time on Type 1 SMT creep-fatigue life of Alloy 617 ..................................... 13

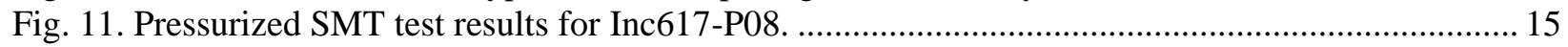

Fig. 12. Effect of internal pressure on SMT with combined tension and compression hold at 950 ${ }^{0} \mathrm{C}$.

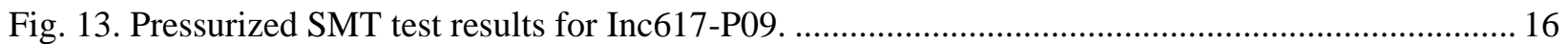

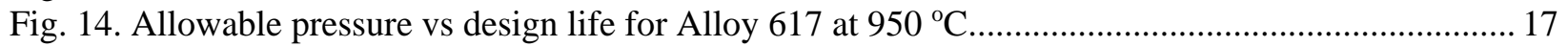

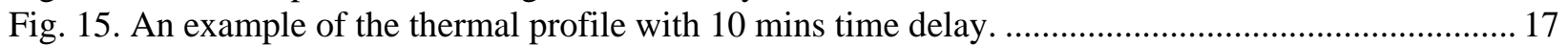

Fig. 16. EPP Strain limits envelope and test data for $405{ }^{\circ} \mathrm{C}$ to $705^{\circ} \mathrm{C}$ temperature range (the green symbol $\odot$ passed $1 \%$ strain limits, while the red symbol $\otimes$ did not pass $1 \%$ strain

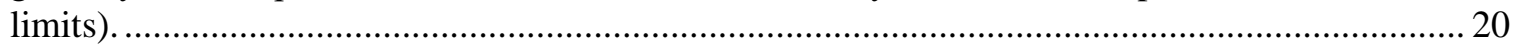

Fig. 17. Hysteresis loops of the two bars with $-250 \mathrm{lb}$ and $3 \mathrm{~min}$ delay loading condition. ..................... 22

Fig. 18. Hysteresis loops of the two bars with $550 \mathrm{lb}$ and $3 \mathrm{~min}$ delay loading condition. ...................... 22

Fig. 19. Hysteresis loops of the two bars with $50 \mathrm{lb}$ and $10 \mathrm{~min}$ delay loading condition. ....................... 23

Fig. 20. Hysteresis loops of the two bars with $150 \mathrm{lb}$ and $10 \mathrm{~min}$ delay loading condition. ..................... 23

Fig. 21. Hysteresis loops of the two bars with $300 \mathrm{lb}$ and $10 \mathrm{~min}$ delay loading condition. ..................... 23 


\section{LIST OF TABLES}

Table 1. Chemical compositions of Alloy 617 plate with heat number 314626 (weight \%), .................... 3

Table 2. Chemical compositions of SS316H bar with heat number 101076 (weight \%)............................5

Table 3. Parameters of the two-bar experiment and EPP analysis.................................................... 7

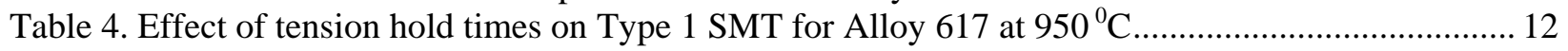

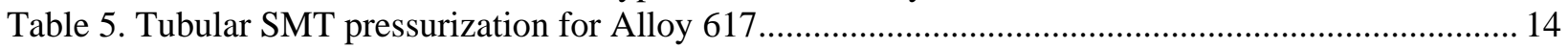

Table 6. Comparison of the pressurization SMT on Alloy 617 .......................................................... 14 


\section{ACRONYMS}

$\begin{array}{ll}\text { ART } & \text { Advanced Reactor Technologies Program } \\ \text { ASME } & \text { American Society of Mechanical Engineers } \\ \text { B\&PV } & \text { Boiler and Pressure Vessel } \\ \text { CC } & \text { Code Case } \\ \text { CF } & \text { Creep-Fatigue } \\ \text { DOE } & \text { Department of Energy } \\ \text { EPP } & \text { Elastic-Perfectly Plastic } \\ \text { ORNL } & \text { Oak Ridge National Laboratory } \\ \text { SMT } & \text { Simplified Model Test }\end{array}$




\section{ACKNOWLEDGMENTS}

This research was sponsored by the U.S. Department of Energy (DOE), Office of Nuclear Energy (NE), Advanced Reactor Technologies (ART) Program. We gratefully acknowledge the support provided by Brian Robinson of DOE-NE, Advanced Reactor Technologies, ART Program Manager; William Corwin of DOE-NE, ART Materials Technology Lead; Hans Gougar of Idaho National Laboratory (INL), ART Co-National Technical Director; and Richard Wright of INL, Technical Lead, High Temperature Materials.

Helpful discussions with Mark C. Messner of Argonne National Laboratory and his technical input on EPP analysis are acknowledged. Technical support from Shane Hawkins and Seth Baird of Oak Ridge National Laboratory (ORNL) is greatly appreciated. The time spent by Lianshan Lin, Hong Wang and Edgar Lara-Curzio of ORNL in reviewing this report is greatly appreciated.

We would also like to acknowledge Richard Wright of INL for supplying the Alloy 617 materials to support the testing task of this work. 


\begin{abstract}
The goal of the proposed integrated Elastic Perfectly-Plastic (EPP) and Simplified Model Test (SMT) methodology is to incorporate a SMT data-based approach for creep-fatigue damage evaluation into the EPP methodology to avoid the separate evaluation of creep and fatigue damage and eliminate the requirement for stress classification in current methods; thus greatly simplifying evaluation of elevated temperature cyclic service. The purpose of this methodology is to minimize over-conservatism while properly accounting for localized defects and stress risers. To support the implementation of the proposed methodology and to verify the applicability of the code rules, thermomechanical tests continued in FY17. This report presents the recent test results for Type 1 SMT specimens on Alloy 617 with long hold times, pressurization SMT on Alloy 617, and two-bar thermal ratcheting test results on SS316H at the temperature range of $405{ }^{\circ} \mathrm{C}$ to $705{ }^{\circ} \mathrm{C}$. Preliminary EPP strain range analysis on the two-bar tests are critically evaluated and compared with the experimental results.
\end{abstract}




\section{BACKGROUND}

The goal of the EPP-SMT approach is to incorporate an SMT data-based approach for creep-fatigue (CF) damage evaluation into the EPP methodology to avoid the use of the " $\mathrm{D}$ " diagram and to minimize overconservatism while properly accounting for localized defects and stress risers. There are two approaches of interest to the proposed integrated evaluation of cyclic service life that have received attention over the last several years. One of these approaches is identified as the Elastic-Perfectly Plastic (EPP) methodology and the other is identified as the Simplified Model Test (SMT) methodology. The EPP cyclic service methodology greatly simplifies the design evaluation procedure by eliminating the need for stress classification that is the basis of the current rules. However, the EPP methodology for evaluation of creep-fatigue damage still requires the separate evaluation of creep damage and fatigue damage by placing a limit on the allowable combined damage, the " $\mathrm{D}$ " diagram based on calculating individual creep and fatigue damages.

A detailed plan in developing this methodology has identified the key issues, assumptions and the proposed path to resolution and verification of the EPP-SMT approach. EPP-based design methods have already been qualified for ASME Sec. III Div. 5 applications via approved two code cases: strain limits code case (EPP strain limits CC N-861) and EPP creep-fatigue code case (EPP C-F CC N-862). Fig. 1 is an updated flow chart from the initial plan (Wang, et. al., 2016, Wang, et. al., 2017b) and it shows the impact of recent test results from pressurization SMT and the EPP strain range analysis. The major elements in this flow chart include: three key assumptions that have been made to move forward; the near-term test and evaluation actions required to validate these assumptions; and the lon-term test and analytical development required depending upon the outcome of the near term validation efforts.

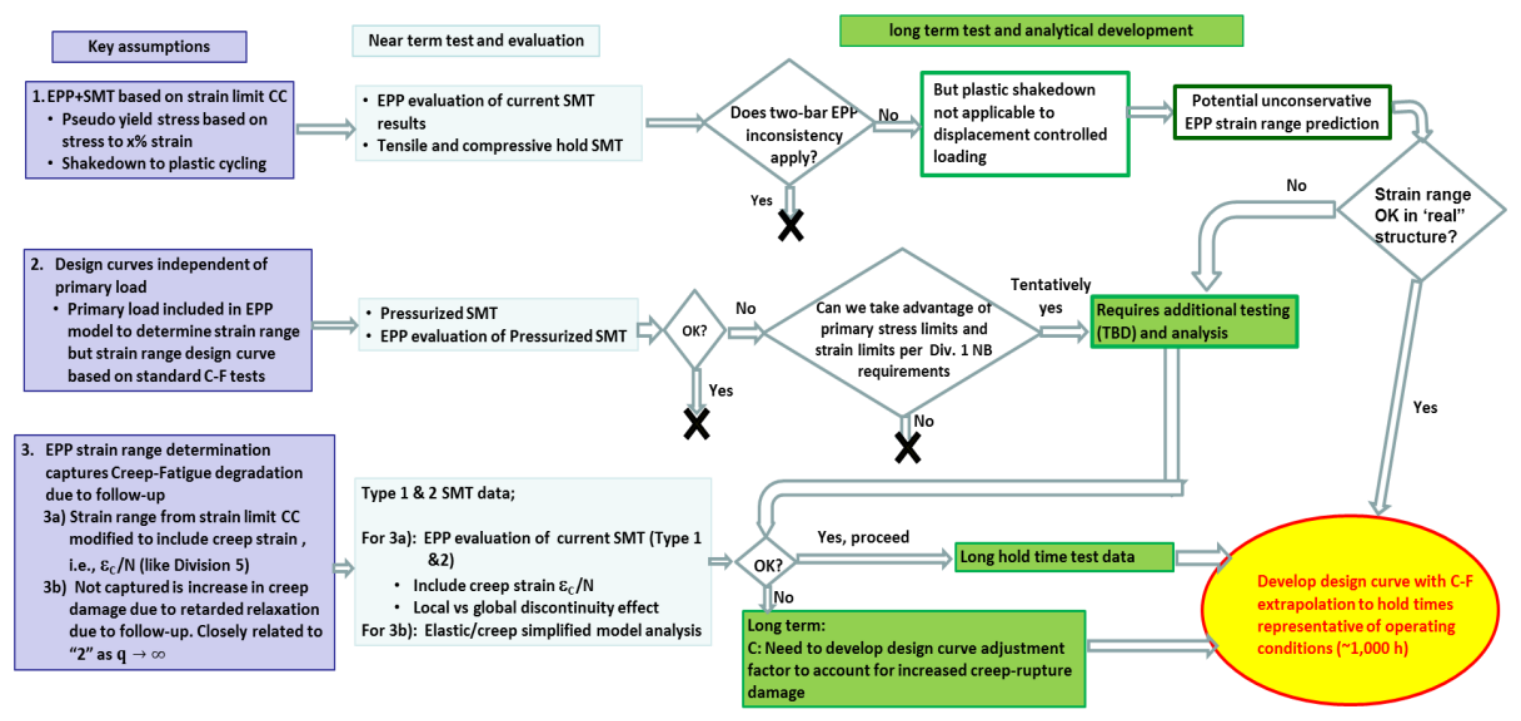

Fig. 1. Updated flow-chart on the development of the EPP-SMT approach.

Shown under the category of "Near-term test and evaluation" for assumption 1, is a comparison of tension hold data with data from tests with alternating tension and compression hold times. The reason for this is twofold. First, it would be desirable to base the validation on the more conservative data. However, perhaps the more important reason is to minimize the barreling effect that clouds the interpretation of the tension-hold only test data.

Pressurized SMT capsule tests are being used to assess the second assumption that the stress level associated with primary loading will be small compared with the secondary and peak stress levels and 
shouldn't have a significant effect on the total life. In addition to the pressurized SMT data, the modified two-bar test with one bar as SMT specimen at constant temperature and the second bar a smooth gage geometry, under Long-Term Tests, will provide valuable data for verification of the effects of superimposed primary loading. The advantage of this two-bar modified configuration is that all the relevant test parameters can be measured directly. If it turns out that the effect of primary loading is significant, then the proposed solution, as shown under the long-term test and analytic development column, is to develop mean stress type design curves analogous to the mean stress correction curves for the fatigue evaluation of some materials below the creep regime.

The third assumption, that the EPP strain range determination captures the creep-fatigue degradation due to follow-up effects, will be evaluated using results from both the Type 1 and 2 SMT test specimens to determine if adjustment factors will be required for the SMT based design curves

Longer term tests are required to develop the SMT design curves and to support the development of adjustment factors to account for such effects as sustained primary loading and retardation of stress relaxation due to follow-up, if needed.

This report presents the recent SMT test results on Alloy 617 and two-bar thermal ratcheting test results on SS316H. Preliminary EPP strain range analysis on the two-bar tests are critically evaluated. The tests and analysis in this report are critical in developing of this integrated EPP-SMT design approach. 


\section{EXPERIMETNAL DETAILS}

\subsection{SMT AND PRESSURIZED SMT FOR ALLOY 617}

All the SMT and pressurized SMT experiments performed in this study used the same Alloy 617 plate from Heat 314626 from ThyssenKrupp VDM USA, Inc., with nominal thickness of 1.5”. The plate allows one of the SMT solid bar specimen and tubular pressurization specimen be prepared from the thickness. The chemical composition of the plate is listed in Table 1. The specimen longitudinal direction is oriented with the rolling direction of the plate. All the specimens were tested in the as-received condition.

Table 1. Chemical compositions of Alloy 617 plate with heat number 314626 (weight \%).

\begin{tabular}{c|c|c|c|c|c|c|c|l|l|l|l|c}
\hline $\mathbf{C}$ & $\mathbf{S}$ & $\mathbf{C r}$ & $\mathbf{N i}$ & $\mathbf{M n}$ & $\mathbf{S i}$ & $\mathbf{M o}$ & $\mathbf{T i}$ & $\mathbf{C u}$ & $\mathbf{F e}$ & $\mathbf{A l}$ & $\mathbf{C o}$ & $\mathbf{B}$ \\
\hline 0.05 & $<0.002$ & 22.2 & $\mathrm{R} 54.1$ & 0.1 & 0.1 & 8.6 & 0.4 & 0.04 & 1.6 & 1.1 & 11.6 & $<0.001$ \\
\hline
\end{tabular}

The gage test section of the Type 1 SMT geometry specimens shown in Fig. 2 was the same as what was previously tested for Type 1 SMT on Alloy 617. The tab diameter was reduced to better utilize supply material plate. The control length for the applied displacement was 5 in to achieve the designed elastic follow up. The average strain was measured using a 0.4 in gage extensometer placed inside the necked test section. The measured axial strains were used to generate the hysteresis loops along with the applied stresses.

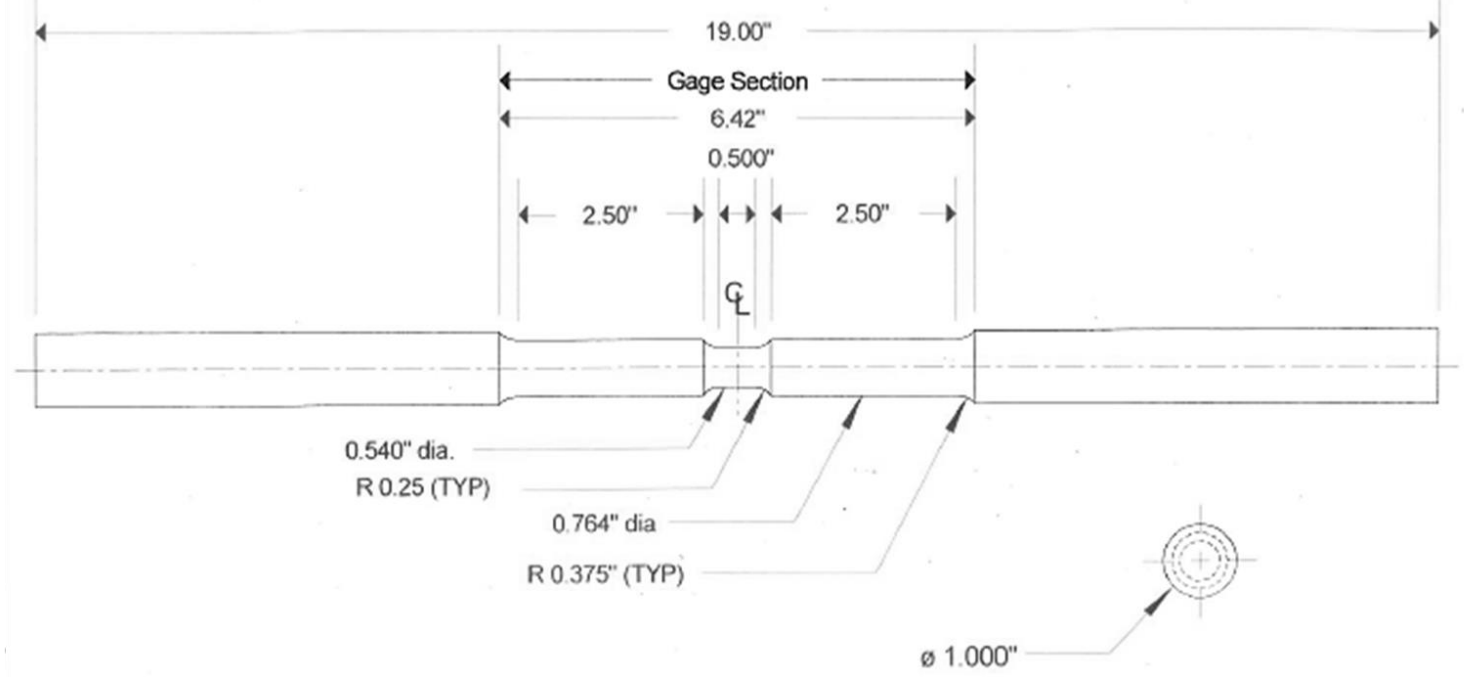

Fig. 2. Type 1 SMT solid bar specimen geometry for Alloy 617. Units are in inches. 


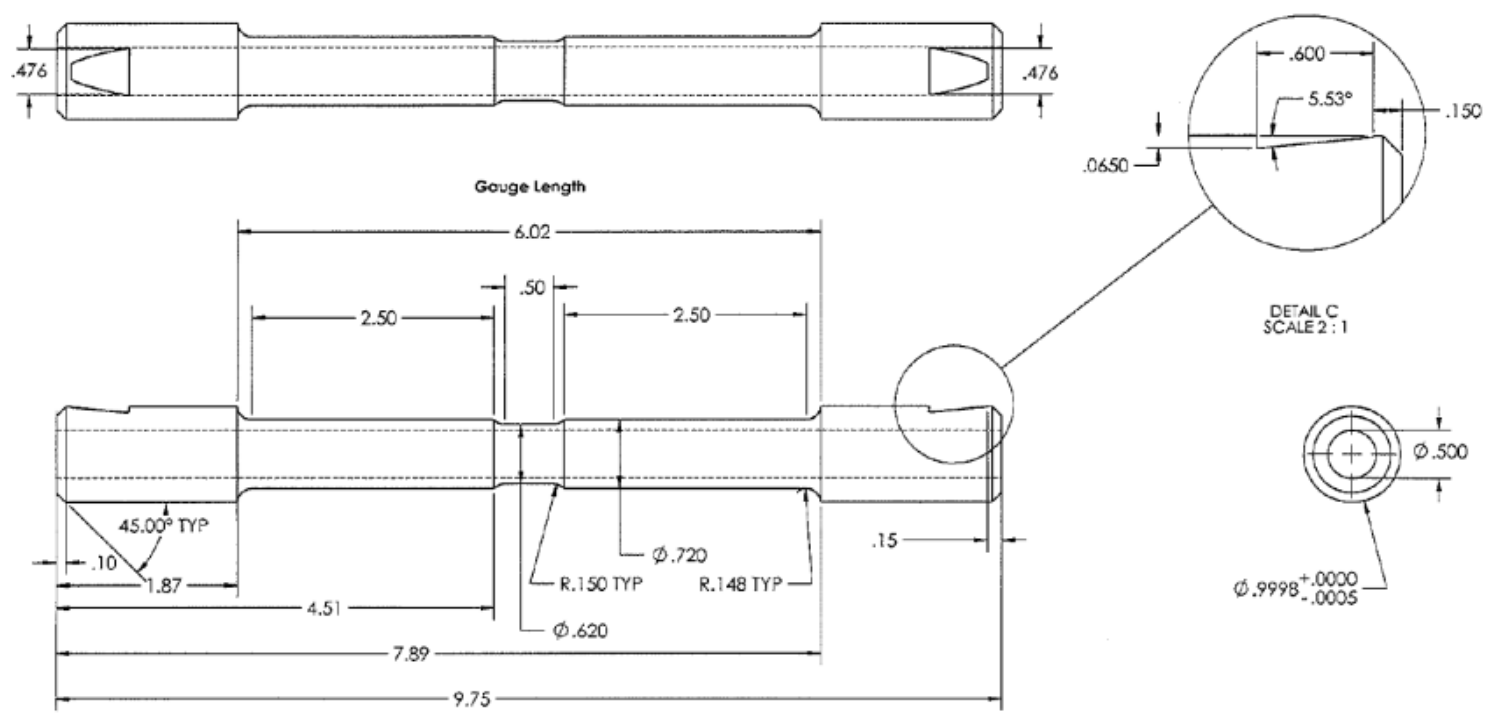

Fig. 3. Center test section of the pressurization SMT specimen for Alloy 617. Units are in inches.

There are two types of end-displacement profiles used for the SMT creep-fatigue testing in this report, and they are fully reversed loading with peak tension hold or combined peak tension and peak compression hold (schematically shown in Fig. 4). The loading was automated through a LabVIEW program. The loading segment was $3 \mathrm{~s}$, and the same unloading rate was applied. For the experiments with hold times for $600 \mathrm{~s}$ (10 min), 1,800 s (30 min) and 36,000 s (10 hr) on Type 1 SMT, tension only profile shown in Fig. 4a was used. The pressurized SMT test on INC617-P09 used a tension hold of $600 \mathrm{~s}$ (10 min) loading (Fig. 4a), and combined tension hold and compression hold of $600 \mathrm{~s}$ (10 min) each (Fig. $4 \mathrm{~b})$. The combined tension and compression hold was to minimize the barreling of the necked test section shown in the previous tension hold tests (Wang, et. al., 2016). 


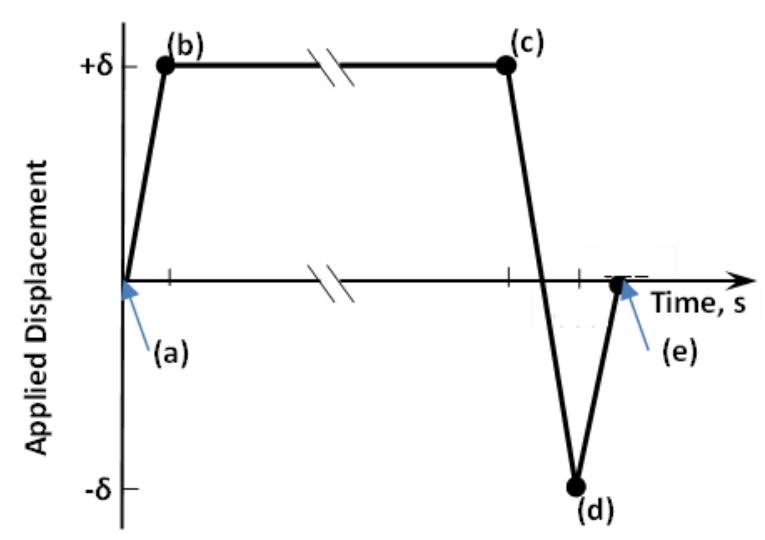

(a)

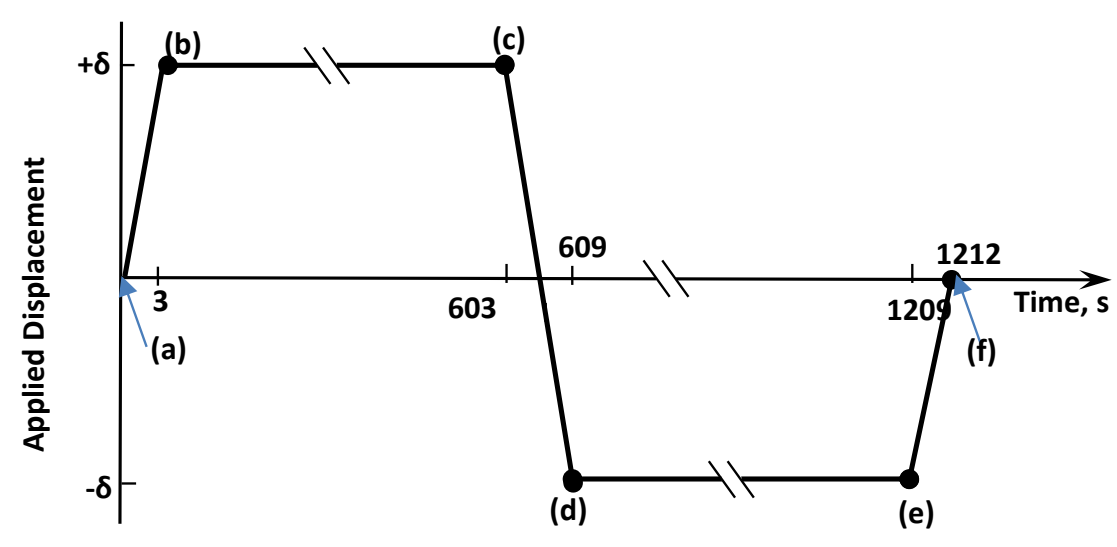

(b)

Fig. 4. Applied end-displacement profile for one cycle of SMT creep-fatigue testing with tension hold (a) and combined tensile-compression hold (b).

\subsection{TWO-BAR THERMAL RATCHETING ON SS316H}

\subsubsection{Two-bar thermal ratcheting experiment}

316H stainless steel (SS316H) was chosen for the experiment primarily because it has been well characterized and it is a material of interest for advanced reactor systems. SS316H round bar material with nominal diameter of 1 in was previously purchased from Outokumpu Stainless Bar, LLC. The heat number is 101076 and the as-received SS316H bar satisfies specification ASME SA497. The chemical composition of the SS316H is listed in Table 2. All the specimens were tested in the as-received condition. The specimen geometry is shown in Fig. 5.

Table 2. Chemical compositions of SS316H bar with heat number 101076 (weight \%).

\begin{tabular}{c|c|c|c|c|c|c|c|c|c|c}
\hline $\mathbf{C}$ & $\mathbf{P}$ & $\mathbf{S i}$ & $\mathbf{N i}$ & $\mathbf{M n}$ & $\mathbf{N}$ & $\mathbf{T i}$ & $\mathbf{S n}$ & $\mathbf{V}$ & $\mathbf{F e}$ & $\mathbf{C b}-\mathbf{T a}$ \\
\hline 0.045 & 0.028 & 0.650 & 10.120 & 1.420 & 0.053 & 0.002 & 0.006 & 0.060 & balance & 0.014 \\
\hline $\mathbf{S}$ & $\mathbf{C r}$ & $\mathbf{C o}$ & $\mathbf{M o}$ & $\mathbf{N b}$ & $\mathbf{A l}$ & $\mathbf{B}$ & & & & \\
\hline 0.024 & 16.230 & 0.279 & 2.090 & 0.014 & 0.004 & 0.004 & & & & \\
\hline
\end{tabular}




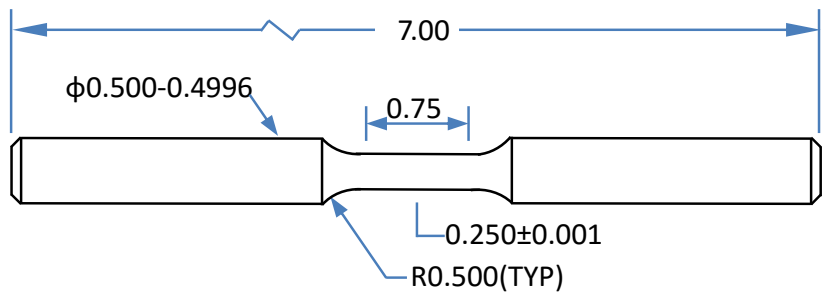

Fig. 5. Specimen geometry the SS316H used in two-bar thermal ratcheting experiments. Units are in inches.

The experimental control logic used is similar to what was previously reported by Swindeman et al. (1982) and is explained in detail in Wang et al. (2013a, 2015, 2016). In this method, two coupled servocontrolled machines are used to implement two bars in a parallel testing condition and the control system forces equal strains in the two specimens, yet allows the applied total load to be constant. The two bars are installed in two, coupled, servo-hydraulic machines with machine \#1 under strain control and machine \#2 under load control. The strain signals measured by the extensometer on Bar 2 are fed into machine \#1 as the command signal for strain control of Bar 1. This control logic ensures equal amount of deformation for the two bars at all time. The driving force for the specimens to experience deformation is the constant total load of the two bars and the cyclic temperature profile applied to each bar. A two-bar model is a simplified analysis of a vessel under a combination of a constant, primary pressure load and a secondary, alternating thermal cycle. The two bars represent two extreme material fibers (see Fig. 6).

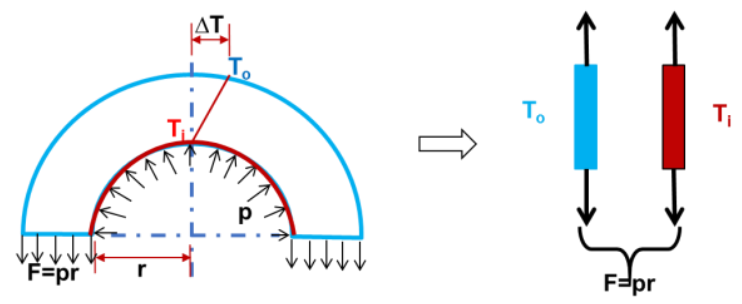

Fig. 6. Pressurized cylinder with radial thermal gradient represented by a two-bar model.

Fig. 7 shows the two-bar thermal cycle. The thermal strains in the specimen are a function of the time delay between (3) to (5), the cooling rate and the total temperature difference. The heating and cooling rates were $30^{\circ} \mathrm{C} / \mathrm{min}$. Table 3 has summarized the parameters used for the two-bar experiments and EPP analysis. Experiments were performed on one set of specimens at the temperature range of $405{ }^{\circ} \mathrm{C}$ to 705 ${ }^{\circ} \mathrm{C}$ with different combinations of total load levels and time delays. The changing of loading conditions was performed at $405{ }^{\circ} \mathrm{C}$ without unloading the specimens to zero load from the previous condition.

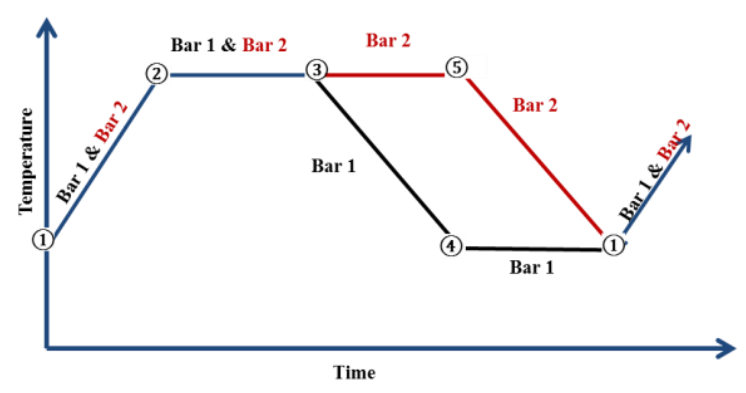

Fig. 7. Two-bar thermal cycle. 
Table 3. Parameters of the two-bar experiment and EPP analysis.

\begin{tabular}{l|l}
\hline Material & $\mathrm{SS} 316 \mathrm{H}$ \\
\hline Specimen diameter & $0.25 \mathrm{in}$ \\
\hline Temperature range & $405^{\circ} \mathrm{C}$ to $705^{\circ} \mathrm{C}$ \\
\hline hold time (2) to (3) & $60 \mathrm{~min}$ \\
\hline $\begin{array}{l}\text { Heating and cooling rate } \\
\text { 1) to (2; (3) to 4) and (5) to (1) }\end{array}$ & $30^{\circ} \mathrm{C} / \mathrm{min}$ \\
\hline time delay, (3) to 5) & From $1 \mathrm{~min}$ to $10 \mathrm{~min}$ \\
\hline Applied total load & From $-1,000 \mathrm{lbs}$ to $1,000 \mathrm{lbs}$ \\
\hline
\end{tabular}

Consistent with the preceding work by Wang et al. (2013a, 2014, 2015, 2016), the ratcheting strain is defined as the difference in the mechanical strain at a time point in a thermal cycle and that at the same time point in the reference cycle. When the same reference point in the thermal cycle is selected, the amount of ratcheting strain calculated based total strain is the same as that calculated based on mechanical strain. In this study, the ratcheting strains were calculated from the maximum total strains of each cycle, and they were approximately the same values when calculated based on the minimum strains. It was also observed that the cyclic ratcheting rates were approximately constant and the shape of the hysteresis loops were uniform for all the tests conducted after the first six initial cycles. In this study, the ratcheting rates were evaluated using the sixth cycle as the reference cycle, and the results were extrapolated to obtain the ratcheting strain at $200 \mathrm{hr}$ to provide information to our parallel theoretical studies on strain limits of SS316H.

\subsubsection{EPP strain limits analysis}

The EPP method assumes that the average deformations computed for a system with an elastic-perfectly plastic analysis using a material's elastic properties and a pseudo-yield stress less than the minimum flow stress the material experiences over its design life will be greater than the actual, experimental deformations. The EPP strain limits code case (ASME B\&PV Code Case N-861) sets this temperature dependent pseudo-yield stress based on the isochronous stress/strain curves for the material defined in the ASME code.

The code case uses this bounding EPP analysis to evaluate designs against the limits on inelastic strain established in the ASME code. Essentially the code case sets two conditions on the results of the analysis:

- the structure must shake down under cyclic loading with no cyclic deformation using a target pseudo yield stress less than or equal to the membrane strain limits of $1 \%$ for base material and $0.5 \%$ for weldments

- if the structure shakes down, the inelastic strain computed by adding inelastic strain from the elastic-perfectly plastic analysis to the afore mentioned target strain must be less than the strain limits.

If a structure meets both these criteria then, by the bounding principal outlined above, the true structure will both shake down and accumulate less than $1 \%$ inelastic strain over its design life. Therefore, the code case deems it to have met the strain limits requirements of Section III, Division 5, HBB-T-1310.

This work also uses the EPP strain limits analysis procedure in a slightly different way. Here we compare the strain range computed from EPP analysis to the experimental strain ranges found in corresponding experiments. The idea is that the strain range computed by the elastic-perfectly plastic analysis with an 
appropriate temperature-dependent pseudo-yield stress established from the code isochronous curves should be greater than the true experimentally measured strain ranges. 


\section{RESULTS AND DISCUSSIONS}

\subsection{SMT TEST RESULTS ON ALLOY 617}

\subsubsection{Hold time effect on type 1 SMT - Alloy 617}

The conventional creep-fatigue interaction diagram is generated using strain-controlled fatigue tests with variable strain ranges and hold times in tension and compression. Lower strain ranges and longer hold times increase creep damage, whereas, fatigue dominates at higher strain ranges and short hold times. Changes in dominating damage mode in creep-fatigue experiments are often accompanied with differences in failure mode which can be confirmed by evidence of creep cavitation and/or fatigue cracking. As the hold time is increased, the strain-controlled creep-fatigue cycle life will approach saturation and the stress relaxation process saturates and the stress reaches a constant value. For creepfatigue experiments with very long hold time and only occasionally imposed cycles, the process can be treated as pure stress relaxation. For standard strain controlled creep-fatigue on Alloy 617 at $950{ }^{\circ} \mathrm{C}$, Carrol et. al. (2011) demonstrated that increasing the duration of the hold time from $180 \mathrm{~s}$ to $1800 \mathrm{~s}$ did not significantly reduce the cycle life, indicating that the number of cycles to failure in creep-fatigue reaches saturation and is independent of increasing hold time.

However, creep-fatigue evaluation using the SMT methodology takes into account stress and strain redistribution in a component due to elastic follow-up. In our previous experimental study (Wang, et.al., 2013b), it is demonstrated the elastic follow-up results in: 1) retardation of stress relaxation during hold and therefore accelerates creep damage, and 2) a non-linear increase in localized strain accumulation. The effect of hold time on SMT is therefore evaluated in this report in support of the goal of developing of SMT based creep-fatigue design curves with extrapolation to hold times representative of operation conditions $(\sim 1,000 \mathrm{hr}$ of hold time).

Two SMT creep-fatigue tests were performed with Type 1 geometry with tension hold times of $1800 \mathrm{~s}$ ( $30 \mathrm{~min}$ ) for test \#37 and $36,000 \mathrm{~s}(10 \mathrm{hr})$ for test $\# 38$ at $950^{\circ} \mathrm{C}$. Both tests had an elastically calculated strain range of $0.3 \%$. The $10 \mathrm{hr}$ hold time test is the longest hold time test for Alloy 617 at $950{ }^{\circ} \mathrm{C}$. Shown in Fig. 8 and Fig. 9 are plots of the measured strain range and maximum (tension) and minimum (compressive) stress as a function of cycle number, representative hysteresis loops, stress history, ratcheting strain and picture of the failed specimen test \#37 and \#38. The SMT \#37 failed at about 230 cycles or $115.8 \mathrm{hr}$. Test \#37 had SMT creep-fatigue life of 150 cycles or $1500.5 \mathrm{hr}$. The average strains measured at the necked test section were found to be ratcheting to the compression direction for both tests, and the specimens both failed at the transition radius with noticeable barreling. 


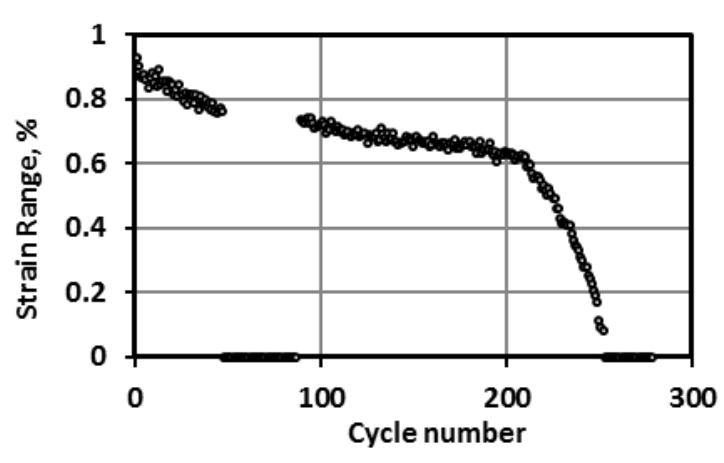

(a) Strain range

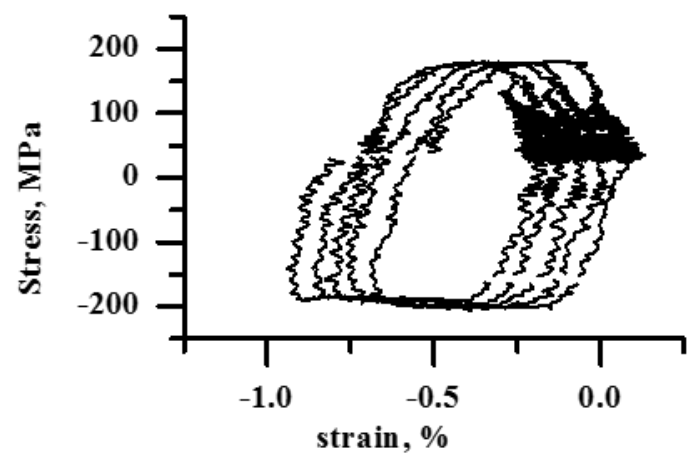

(c) Hysteresis Loop

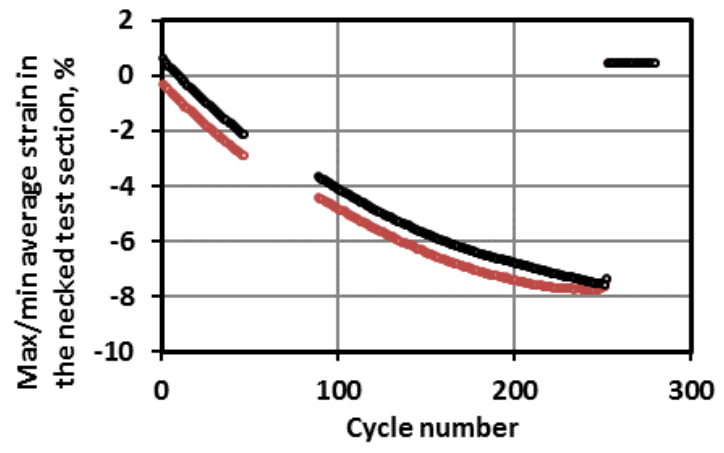

(e) Ratcheting strain

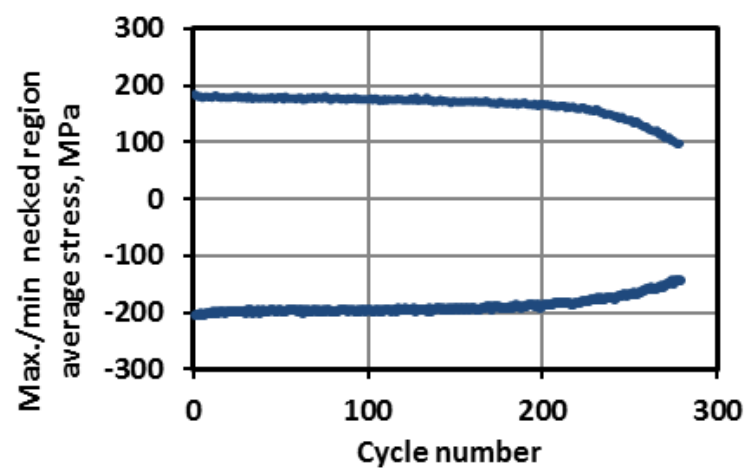

(b) Max/Min stresses

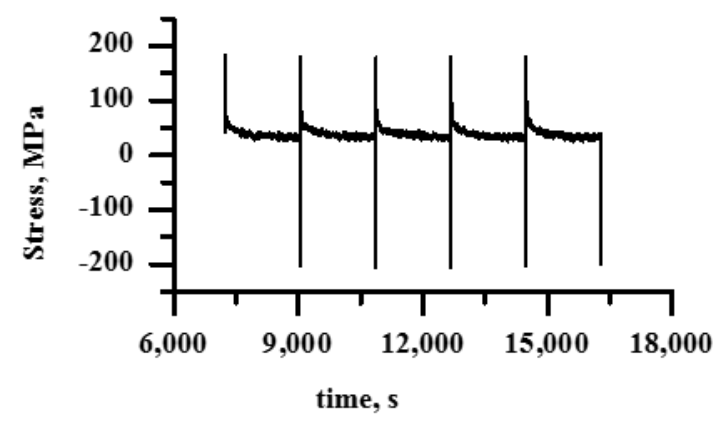

(d) Stress relaxation

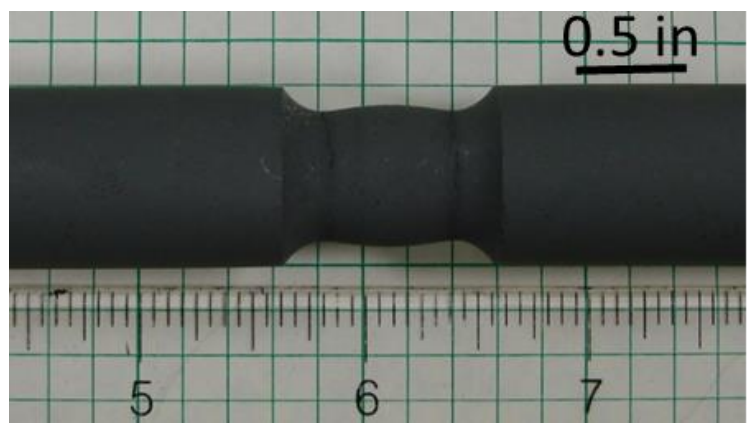

(f) Failed specimen

Fig. 8. Test results for SMT \#37. 


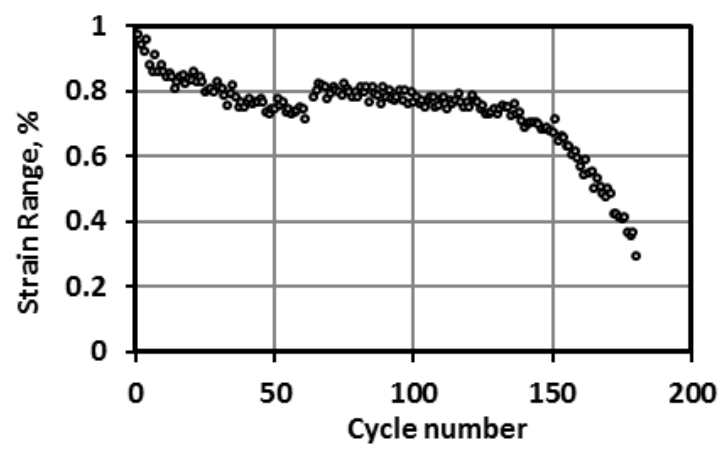

(a) Strain range

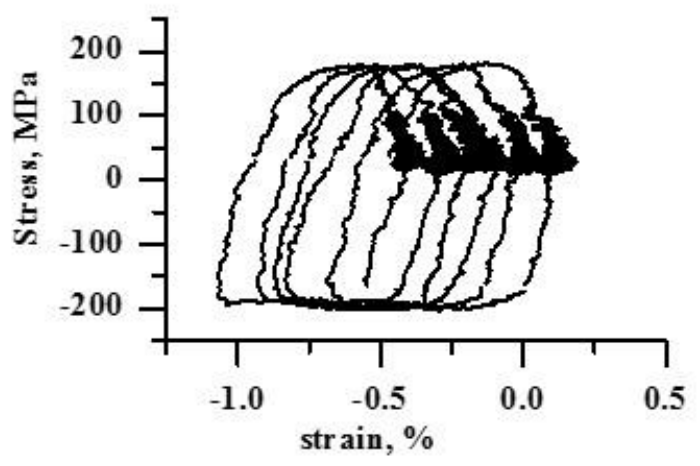

(c) Hysteresis Loop

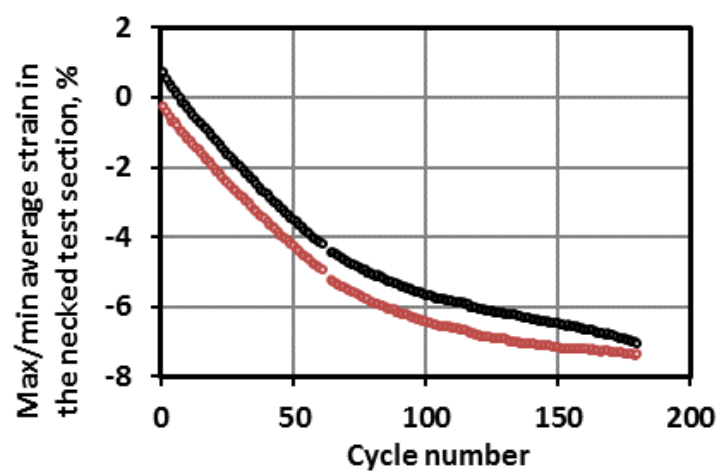

(e) Ratcheting strain

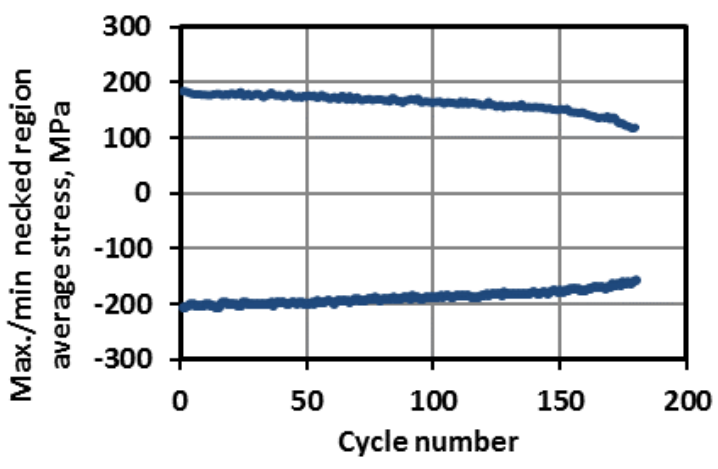

(b) Max/Min stresses

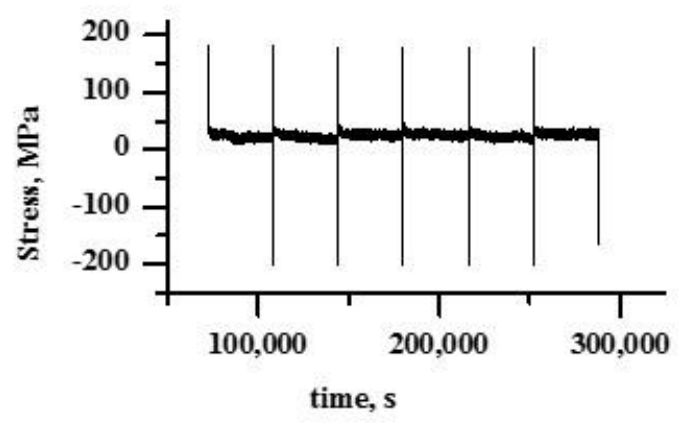

(d) Stress relaxation

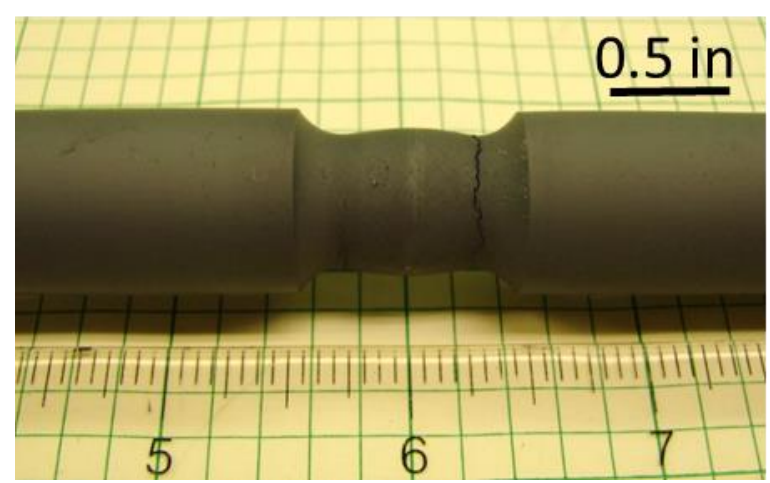

(f) Failed specimen

Fig. 9. Test results for SMT \#38.

The test results are summarized and compared with previous test results with hold time of $600 \mathrm{~s}$ (10 min) in Table 4. When the hold time increased from $10 \mathrm{~min}$ to $30 \mathrm{~min}$, the cycles to failure are reduced by $50 \%$. The $10 \mathrm{hr}$ hold time test showed the lowest cycles to failure, 150, corresponding to a reduction factor of $67 \%$ when compared to the test with $10 \mathrm{~min}$ hold time. The measured strain ranges were larger when the hold time was longer. Although the $10 \mathrm{hr}$ hold time test has the shortest cycles, it does have the longest total test duration, followed by test \# 37 with $30 \mathrm{~min}$ hold. The $10 \mathrm{~min}$ hold time test only had less than $80 \mathrm{hr}$ of cycle life. 
Table 4. Effect of tension hold times on Type 1 SMT for Alloy 617 at $950{ }^{\circ} \mathrm{C}$.

\begin{tabular}{|c|c|c|c|c|c|c|c|}
\hline Test \# & \begin{tabular}{|c|} 
Elastically \\
calculated \\
strain range
\end{tabular} & $\begin{array}{c}\text { Loading } \\
\text { time, } \\
\text { s }\end{array}$ & $\begin{array}{c}\text { Hold time, } \\
\text { s }\end{array}$ & $\begin{array}{c}\text { Initial strain } \\
\text { range, }\end{array}$ & $\begin{array}{l}\text { Failure } \\
\text { location }\end{array}$ & $\begin{array}{l}\text { Life time, } \\
\qquad \mathrm{hr}\end{array}$ & $\begin{array}{l}\text { Cycle to } \\
\text { failure }\end{array}$ \\
\hline$\# 1$ & \multirow{4}{*}{$0.3 \%$} & \multirow{4}{*}{ 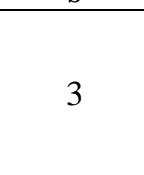 } & 600 & $0.65 \%$ & \multirow{4}{*}{$\begin{array}{l}\text { Transition } \\
\text { radius }\end{array}$} & 78.2 & 460 \\
\hline$\# 2$ & & & 600 & $0.63 \%$ & & 76.5 & 450 \\
\hline \#37 & & & 1,800 & $0.95 \%$ & & 115.8 & 230 \\
\hline \#38 & & & 36,000 & $0.91 \%$ & & 1500.5 & 150 \\
\hline
\end{tabular}

The maximum (tension) and minimum (compressive) stresses, the measured strain and strain range as a function of cycle number and equivalent cycle time are compared for test \#2, \#37 and \#38 in Fig. 10 to demonstrate the effect of hold time on SMT creep-fatigue. The data were shown as a function of cycle number and as a function of the cycle time, to provide different perspectives while comparing these three hold time tests. The stress range of $30 \mathrm{~min}$ hold time test and $10 \mathrm{hr}$ hold time test were the same and were larger than what was shown with 10 min hold test. When the peak stresses of the three hold time tests were compared as a function of cycle time, the degradation rate of the peak stresses was the same before showing a sharp drop prior to failure. All three hold time tests showed ratcheting toward the compression direction. The ratcheting rates as a function of cycle time were the same for the two tests with 10 min hold and $30 \mathrm{~min}$ hold. The strain ranges were found to continuously decrease at the same rate before the sharp drop prior to failure. 


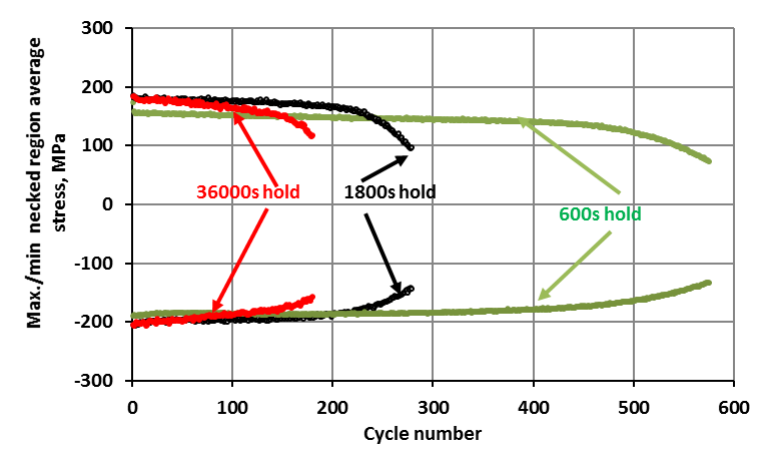

(a)

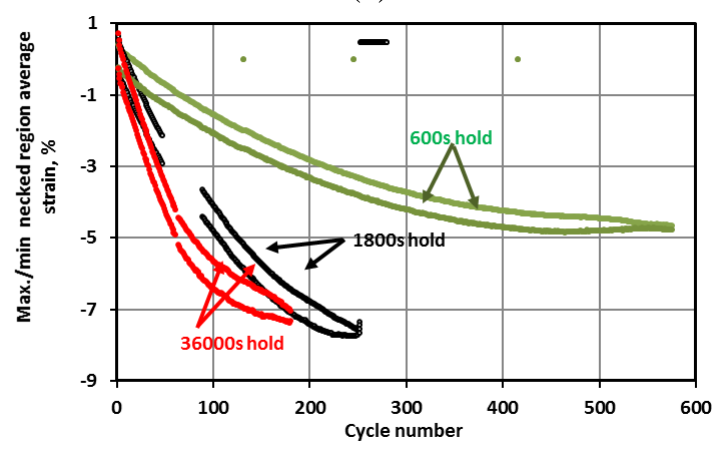

(c)

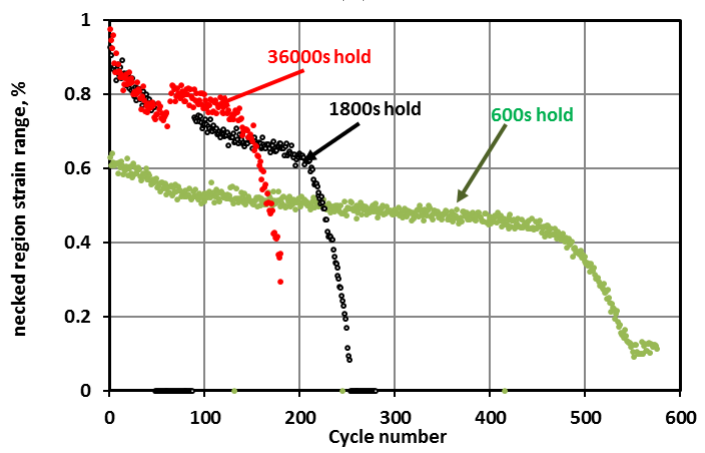

(e)

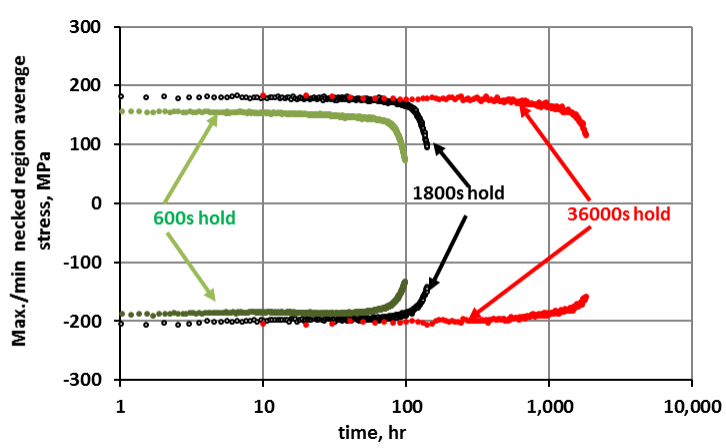

(b)

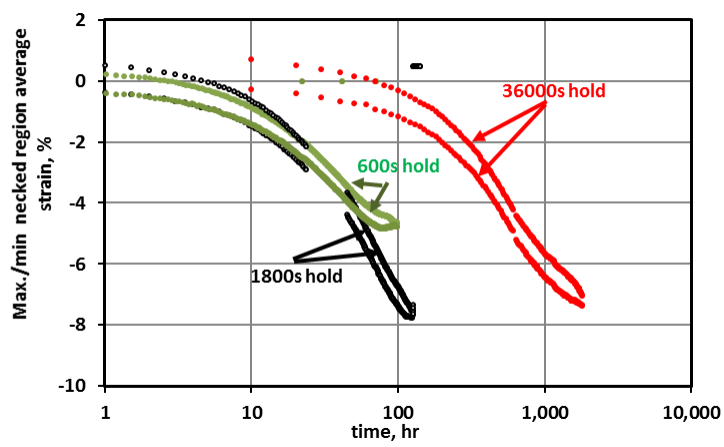

(d)

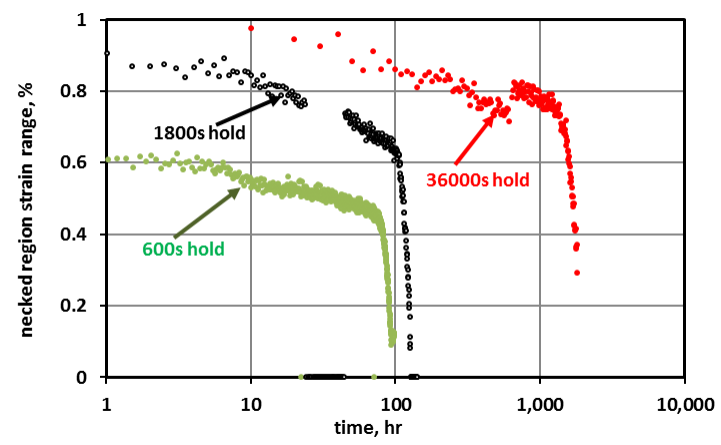

(f)

Fig. 10. Effect of hold time on Type 1 SMT creep-fatigue life of Alloy 617.

\subsubsection{SMT pressurization testing on Alloy 617}

SMT pressurization tests are being used to assess whether the effects of stress levels associated with sustained primary loads will be small when compared to the cyclic secondary and peak levels for the development of SMT creep-fatigue based design curve. In FY17, two additional SMT pressurization tests were performed on Alloy 617. The testing parameters and the results of these two tests are highlighted in Table 5 and Table 6 along with previous pressurized SMT results for comparison. 
Table 5. Tubular SMT pressurization for Alloy 617.

\begin{tabular}{c|c|c|c|c|c|c|c}
\hline $\begin{array}{c}\text { Specimen } \\
\text { ID }\end{array}$ & $\begin{array}{c}\text { Amplitude, } \\
\boldsymbol{\delta} \text { value }\end{array}$ & loading condition & $\begin{array}{c}\text { Initial strain } \\
\mathbf{r a n g e}\end{array}$ & $\begin{array}{c}\text { Test temperature } \\
\mathbf{0}\end{array}$ & $\begin{array}{c}\text { Internal } \\
\text { pressure }\end{array}$ & $\begin{array}{c}\text { Life time, } \\
\mathbf{h r}\end{array}$ & $\begin{array}{c}\text { Cycles to } \\
\text { failure }\end{array}$ \\
\hline INC617-P01 & $4.5 \mathrm{mil}$ & Tension hold 600 s & $0.8 \%$ & 950 & $2 \mathrm{psi}$ & 37.4 & 220 \\
\hline INC617-P02 & $4.5 \mathrm{mil}$ & Tension hold 600 s & $0.8 \%$ & 959 & $200 \mathrm{psi}$ & 37.4 & 220 \\
\hline INC617-P04 & $4.5 \mathrm{mil}$ & Tension hold 600 s & $0.8 \%$ & 957 & $500 \mathrm{psi}$ & 34 & 200 \\
\hline INC617-P03 & $4.5 \mathrm{mil}$ & Tension hold 600 s & $0.75 \%$ & 958 & $750 \mathrm{psi}$ & 25.5 & 150 \\
\hline INC617-P06 & $4.5 \mathrm{mil}$ & Tension hold 600 s & $0.8 \%$ & 950 & $750 \mathrm{psi}$ & 23.8 & 140 \\
\hline INC617-P09 & $3 \mathrm{mil}$ & Tension hold 600 s & --- & 953 & $750 \mathrm{psi}$ & 54.4 & 320 \\
\hline & & & & & & & \\
\hline INC617-P05 & $4.5 \mathrm{mil}$ & $\begin{array}{c}\text { Combined tension } \\
\text { and compression }\end{array}$ & $1 \%$ & 955 & $2 \mathrm{psi}$ & 107.7 & 320 \\
\hline INC617-P08 & $4.5 \mathrm{mil}$ & $\begin{array}{c}\text { Combined tension } \\
\text { and compression }\end{array}$ & $1.05 \%$ & 950 & $500 \mathrm{psi}$ & 94.3 & 280 \\
\hline INC617-P07 & $4.5 \mathrm{mil}$ & $\begin{array}{c}\text { Combined tension } \\
\text { and compression }\end{array}$ & $1.05 \%$ & 950 & $750 \mathrm{psi}$ & 60.6 & 180 \\
\hline
\end{tabular}

Table 6. Comparison of the pressurization SMT on Alloy 617.

\begin{tabular}{|c|c|c|c|c|c|c|c|}
\hline $\begin{array}{l}\text { Specimen } \\
\text { ID }\end{array}$ & $\begin{array}{l}\text { Internal } \\
\text { pressure }\end{array}$ & $\begin{array}{c}\text { Original } \\
\text { ID/OD }\end{array}$ & $\begin{array}{c}\text { Original } \\
\text { wall } \\
\text { thickness }\end{array}$ & $\begin{array}{c}\text { Max OD after } \\
\text { testing }\end{array}$ & $\begin{array}{c}\text { Wall } \\
\text { thickness } \\
\text { after failure }\end{array}$ & Failure location & $\begin{array}{c}\text { Elastic } \\
\text { follow-up } \\
\text { factor }\end{array}$ \\
\hline \multicolumn{8}{|c|}{ Tension hold SMT } \\
\hline INC617-P01 & $2 \mathrm{psi}$ & $0.5 \mathrm{in} / 0.62 \mathrm{in}$ & 60mil & $\sim 0.68 \mathrm{in}$ & $\sim 68 \mathrm{mil}$ & Center & $\begin{array}{l}.8 \\
\sim\end{array}$ \\
\hline INC617-P02 & $200 \mathrm{psi}$ & $0.5 \mathrm{in} / 0.62 \mathrm{in}$ & 60mil & $\sim 0.72$ in & $\sim 62 \mathrm{mil}$ & Center & $\sim 3.8$ \\
\hline INC617-P04 & $500 \mathrm{psi}$ & $0.5 \mathrm{in} / 0.62 \mathrm{in}$ & 60mil & $\sim 0.75 \mathrm{in}$ & $\begin{array}{l}\text { 54mil } \\
\end{array}$ & Center & $\sim 4.0$ \\
\hline INC617-P03 & $750 \mathrm{psi}$ & $0.5 \mathrm{in} / 0.62 \mathrm{in}$ & 60mil & $\sim 0.81$ in & $\sim 41 \mathrm{mil}$ & Transition radius & $\sim 4.1$ \\
\hline INC617-P06 & $750 \mathrm{psi}$ & $0.5 \mathrm{in} / 0.62 \mathrm{in}$ & $60 \mathrm{mil}$ & $\sim 0.80 \mathrm{in}$ & $\sim 42 \mathrm{mil}$ & Transition radius & $\sim 4.1$ \\
\hline INC617-P09 & $750 \mathrm{psi}$ & $0.5 \mathrm{in} / 0.62 \mathrm{in}$ & $60 \mathrm{mil}$ & $\sim 0.78$ in & $\sim 42 \mathrm{mil}$ & Transition radius & --- \\
\hline \multicolumn{8}{|c|}{ Combined Tension and Compression hold SMT } \\
\hline INC617-P05 & $2 \mathrm{psi}$ & $0.5 \mathrm{in} / 0.62 \mathrm{in}$ & 60mil & $\sim 0.64$ in & 59 to $62 \mathrm{mil}$ & Center & --- \\
\hline INC617-P08 & $550 \mathrm{psi}$ & $0.5 \mathrm{in} / 0.62 \mathrm{in}$ & $60 \mathrm{mil}$ & $\sim 0.92$ in & 50 to $35 \mathrm{mil}$ & All over & --- \\
\hline INC617-P07 & $750 \mathrm{psi}$ & $0.5 \mathrm{in} / 0.62 \mathrm{in}$ & $60 \mathrm{mil}$ & $\sim 0.95$ in & 43 to $34 \mathrm{mil}$ & All over & --- \\
\hline
\end{tabular}

INC617-P08 was tested at internal pressure of 500 psi and with combined tension and compression holds of $10 \mathrm{~min}$ each. The $4.5 \mathrm{mil}$ loading amplitude over the 5 in control length for this test corresponds to an elastically calculated strain range of $0.3 \%$ inside the necked test section. At $950{ }^{\circ} \mathrm{C}$, the initial strain range measured was shown to be approximately the same as those tested at a higher internal pressure of $750 \mathrm{psi}$ and a lower internal pressure of 2psi. At 4.5 mil loading amplitude, the strain ranges with combined tension and compression loading are about $0.2 \%$ larger than those tested with tension hold for $10 \mathrm{~min}$. The specimen failed at $\sim 280$ cycles or $94.3 \mathrm{hr}$, shorter than INC617-P05 which was tested with 2 psi internal pressure but longer than INC617-P07 which was tested with 750 psi internal pressure. Shown in Fig. 11 are plots of the measured strain range and maximum (tension) and minimum (compressive) stress as a function of cycle number, representative hysteresis loops, stress history, ratcheting strain and picture of the failed specimen. The average strain measured at the necked test section did not change for the first 70 cycles before ratcheting to the tensile direction, and exceeded $1 \%$ ratcheting strain limits after 120 cycles of testing. 


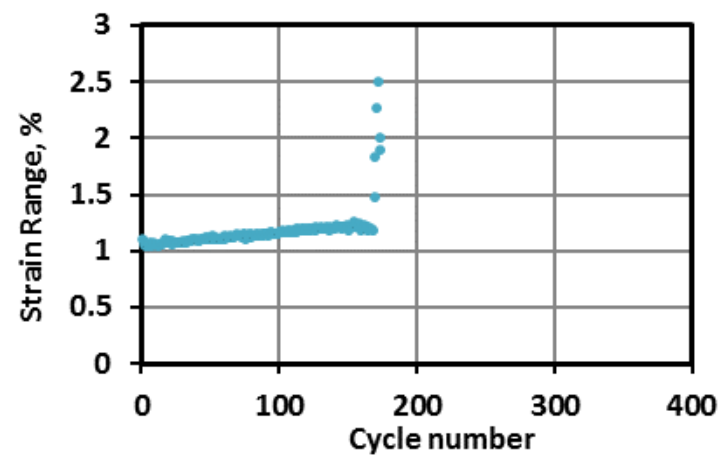

(a) Strain range

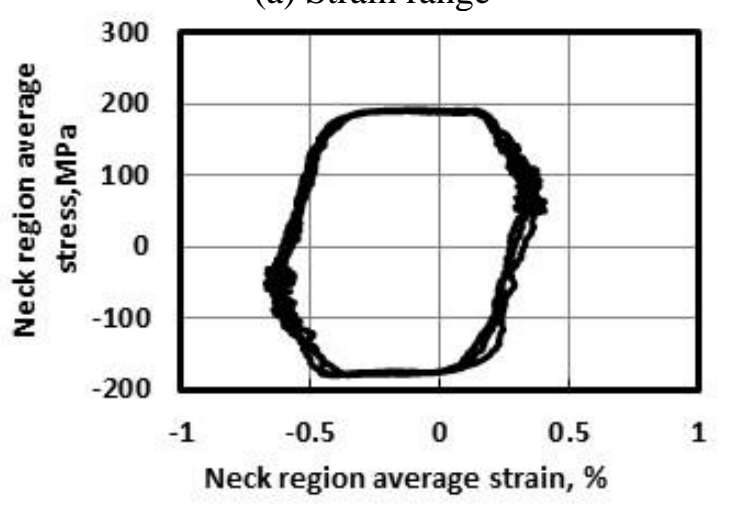

(c) Hysteresis Loop

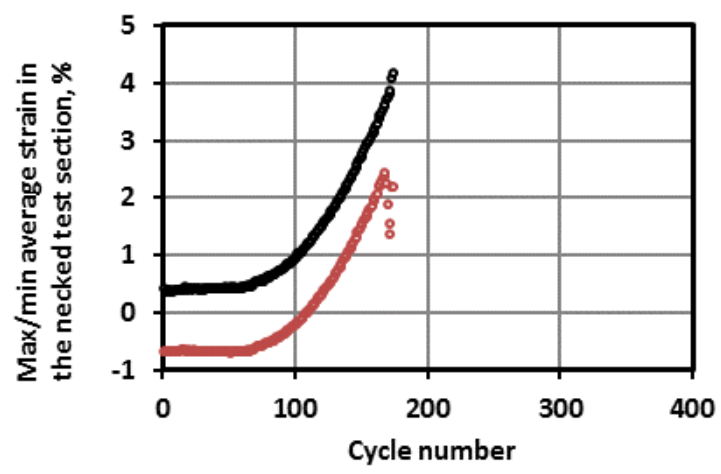

(e) Ratcheting strain

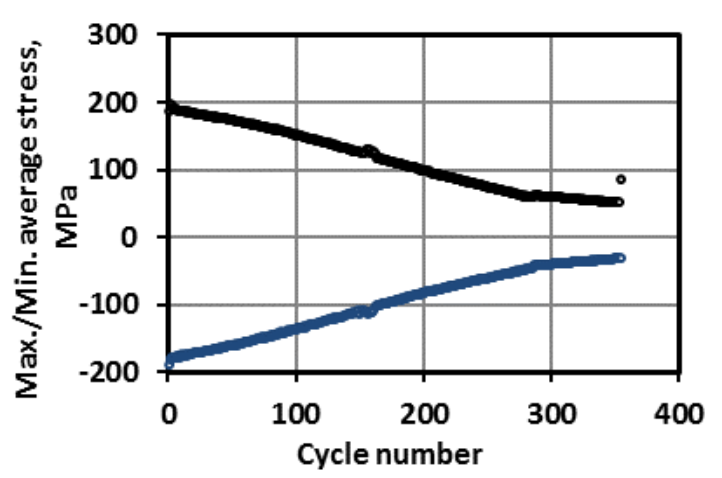

(b) Max/Min stresses

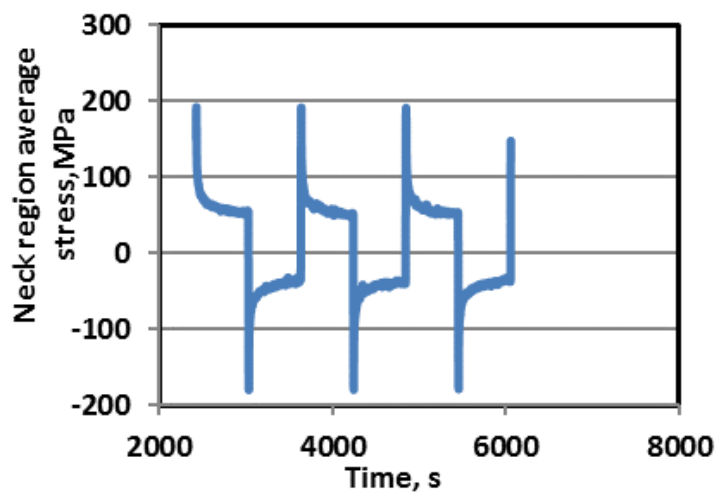

(d) Stress relaxation

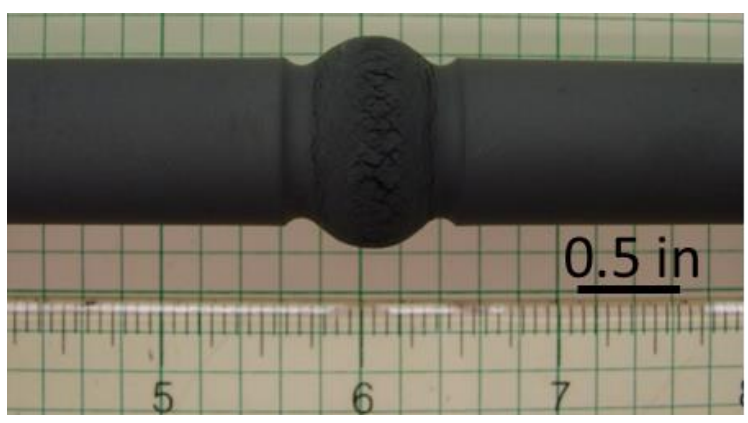

(f) Failed specimen

Fig. 11. Pressurized SMT test results for Inc617-P08.

The maximum (tension) and minimum (compressive) stresses as a function of cycle number with combined tension and compression hold for the three pressurized SMT tests are compared in Fig. 12. The SMT creep fatigue life was reduced by $\sim 43 \%$ when the internal pressure was increased from 2 psi to 750 psi. 


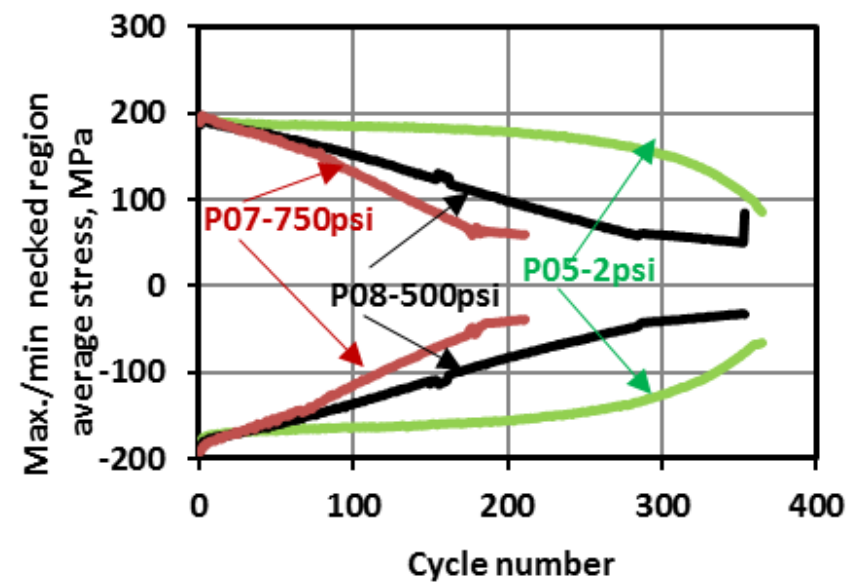

Fig. 12. Effect of internal pressure on SMT with combined tension and compression hold at $950{ }^{\circ} \mathrm{C}$.

INC617-P09 was tested with 750 psi internal pressure at $950{ }^{\circ} \mathrm{C}$ with a lower displacement amplitude of 3 mils over the 5 in control length with tension hold of $10 \mathrm{~min}$. The 3 mils amplitude corresponds to an elastically calculated strain range of $0.2 \%$ in the necked test section. It showed SMT creep-fatigue life of 320 cycles or $54.4 \mathrm{hr}$, about a factor of two when compared to those tested at 4.5 mils amplitude, a reduction ratio similar to what was shown on Type 1 SMT when tested at these two loading levels. The measurement extensometer was not responding properly for this test and only the plot of maximum (tension) and minimum (compressive) stress as a function of cycle number is presented in Fig. 13. The stress response is used as the reference for selection of the failure cycle for this test. A picture of the failed specimen is also shown in Fig. 13. It is noted that the failure location is at the transition radius region where the geometry discontinuity acted as the stress riser. The failure plane is perpendicular to the axial loading direction. For all the tension hold only tests performed on Alloy 617 at $950{ }^{\circ} \mathrm{C}$ (see Table 5 and Table 6), the failure planes are all perpendicular to the axial loading direction and not a longitudinal crack as seen in straight pressurized tests, even at the high internal pressure level of $750 \mathrm{psi}$. This indicates that the cyclic failure mode dominates even at 750psi.

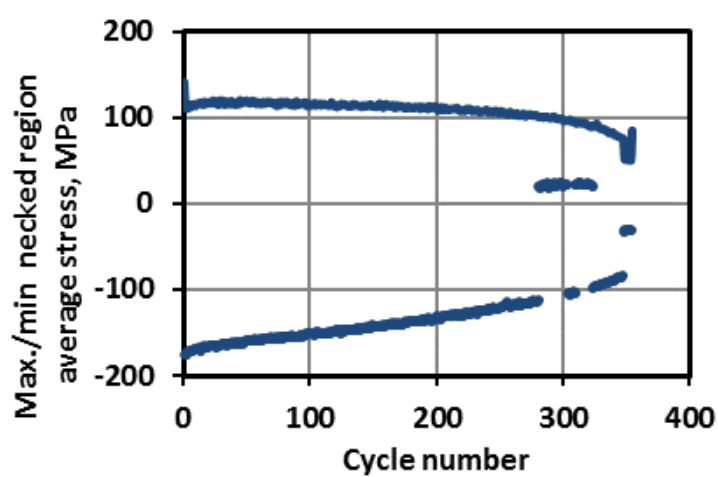

(a)Max/Min stresses

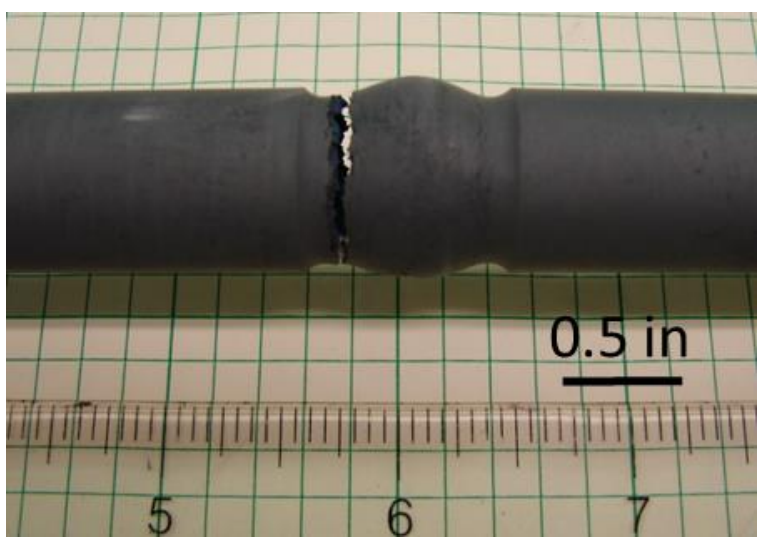

(b) Failed specimen

Fig. 13. Pressurized SMT test results for Inc617-P09. 
Based on the results tabulated in Table 5, it is clear that higher pressures can reduce the number of cycles to failure. However, those pressures may be unrealistically high for normal operating pressure limitations. This potential limitation was assessed by determining the allowable life for pressurized cylinders using the Alloy 617 allowable stress values from a proposed Code Case for Alloy 617 (RC No. 16-994 and 161001). A plot of the allowable pressure vs design life for Alloy 617 at $950{ }^{\circ} \mathrm{C}$ for this testing geometry is shown in Fig. 14, with these three tested pressures highlighted in red. At 200 psi the allowable life is approximately $22,000 \mathrm{hr}$, at $500 \mathrm{psi}$ about $320 \mathrm{hr}$ and only about $60 \mathrm{hr}$ at $750 \mathrm{psi}$. This supports the argument that, for normal design lives of about 30 years with allowable pressure of $\sim 150$ psi, the primary stress evaluation will screen out high pressures that would compromise cyclic life. Clearly additional testing at other strain ranges, temperatures and hold times will be required, but the initial results are encouraging. (Wang, et. al., 2017a).

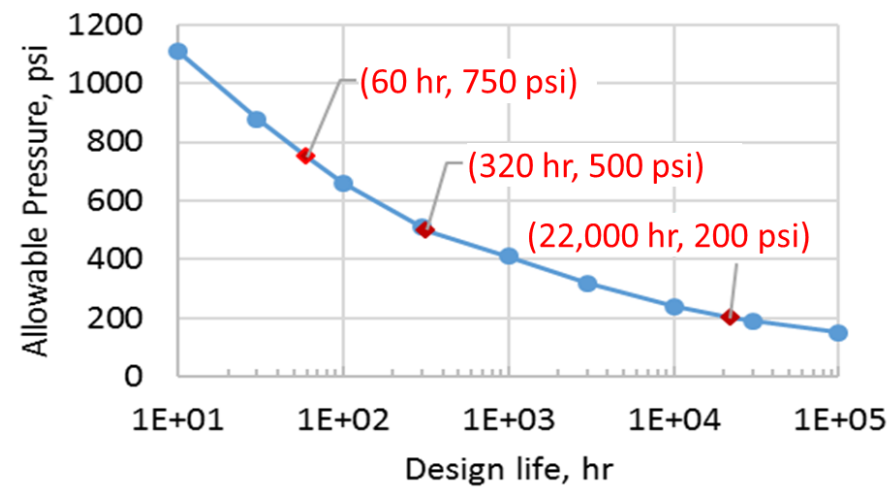

Fig. 14. Allowable pressure vs design life for Alloy 617 at $950{ }^{\circ} \mathrm{C}$

\subsection{TWO-BAR THERMAL RACHETING EXPERIMENTAL AND ANALYTICAL RESULTS ON SS316H}

Two-bar thermal ratcheting tests were performed on SS316H to assess the material response to cyclic thermal loading under two-bar testing conditions at this intermediate temperature range of $405-705^{\circ} \mathrm{C}$. An example of the thermal profile for one cycle is shown in Fig. 15 for testing condition with a 10 min time delay.

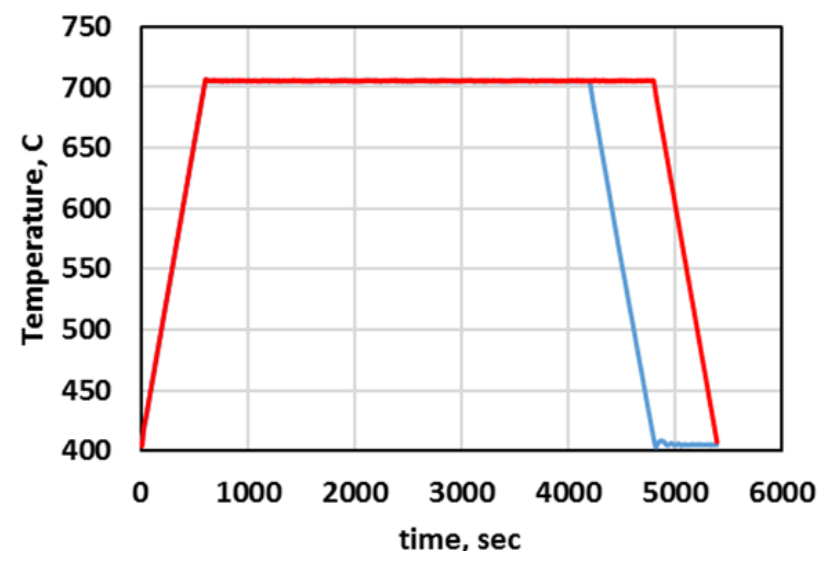

Fig. 15. An example of the thermal profile with 10 mins time delay. 
The experiments were performed on the same set of specimens with sequential test number of T25s-1 to T25s-13. The last test in this group of testing, T25s-13, was with total load of $-550 \mathrm{lbs}$ at 5 -min delay, but it caused buckling of the specimens after 20 cycles due to excessive compressive ratcheting strain accumulation, i.e., based on the available cycles this loading condition would have caused the strain accumulation much greater than $-1 \%$ for a $200 \mathrm{hr}$ projected testing duration. Test T27-1 was performed on a new set of specimens with total load of $450 \mathrm{lbs}$ at 5-min delay. The test parameters and the test results for all the testing conditions except for T25s-13 are summarized in Table 7.

Table 7. Summary of the two-bar thermal ratcheting experiments on SS316H for temperature range of $405^{\circ} \mathrm{C}$ to $705^{\circ} \mathrm{C}$.

\begin{tabular}{l|l|l|l|l|l|l|l}
\hline Test No. & T25s-1 & T25s-2 & T25s-3 & T25s-4 & T25s-5 & T25s-6 & T25s-7 \\
\hline $\begin{array}{l}\text { Applied mean } \\
\text { stress, MPa }\end{array}$ & $3.6 \pm 0.9$ & $10.4 \pm 1.0$ & $21.1 \pm 1.0$ & $31.5 \pm 1.0$ & $-7.3 \pm 1.0$ & $-7.3 \pm 1.0$ & $-17.8 \pm 1.0$ \\
\hline Time delay, min & 10 & 10 & 10 & 10 & 5 & 10 & 3 \\
\hline $\begin{array}{l}\text { Nominal total } \\
\text { load, lbs }\end{array}$ & 50 & 150 & 300 & 450 & -100 & -100 & -250 \\
\hline $\begin{array}{l}\text { Total No. of } \\
\text { cycles tested }\end{array}$ & 33 & 33 & 32 & 32 & 49 & 35 & 48 \\
\hline $\begin{array}{l}\text { Ratcheting rate } \\
\text { per cycle), \% }\end{array}$ & -0.004 & -0.0006 & 0.0035 & 0.039 & -0.0013 & -0.017 & -0.0005 \\
\hline $\begin{array}{l}\text { Initial stress on } \\
\text { Bar 1, MPa }\end{array}$ & 4.6 & -161.5 & -136 & -106.8 & -138.7 & -145.4 & -179.4 \\
\hline $\begin{array}{l}\text { Initial stress on } \\
\text { Bar 2, MPa }\end{array}$ & 2.4 & 183.7 & 179.1 & 169.2 & 123.9 & 130.8 & 141.3 \\
\hline $\begin{array}{l}\text { Initial residual } \\
\text { total strain, \% }\end{array}$ & 0 & -0.35 & -0.34 & -0.12 & 1.23 & 1.11 & 0.31 \\
\hline $\begin{array}{l}\text { Reference cycle } \\
\text { No. }\end{array}$ & 6 & 6 & 6 & 6 & 6 & 6 & 6 \\
\hline $\begin{array}{l}\text { Min. total strain } \\
\text { of the reference } \\
\text { cycle, \% }\end{array}$ & -0.24 & -0.32 & -0.24 & 0.22 & 1.18 & 0.84 & 0.33 \\
\hline $\begin{array}{l}\text { Stress range per } \\
\text { cycle for Bar 1, } \\
\text { MPa }\end{array}$ & $348.8 \pm 2.5$ & $340.6 \pm 2.0$ & $332.8 \pm 1.8$ & $325.8 \pm 1.2$ & $269.4 \pm 1.6$ & $328.3 \pm 1.6$ & $210.2 \pm 1.4$ \\
\hline $\begin{array}{l}\text { Stress range per } \\
\text { cycle for Bar 2, } \\
\text { MPa }\end{array}$ & $345.1 \pm 3.0$ & $335.9 \pm 1.8$ & $328.2 \pm 1.5$ & $321.3 \pm 0.6$ & $265.1 \pm 1.2$ & $323.5 \pm 1.2$ & $205.9 \pm 1.0$ \\
\hline
\end{tabular}


Table 7. continue

\begin{tabular}{l|l|l|l|l|l|l}
\hline Test No. & T25s-8 & T25s-9 & T25s-10 & T25s-11 & T25s-12 & T27-1 \\
\hline $\begin{array}{l}\text { Applied mean } \\
\text { stress, MPa }\end{array}$ & $38.9 \pm 1.0$ & $-38.8 \pm 1.0$ & $-18.2 \pm 1.0$ & $-7.9 \pm 0.8$ & $31.6 \pm 0.8$ & $31.7 \pm 1.1$ \\
\hline Time delay, min & 3 & 3 & 5 & 8 & 7 & 5 \\
\hline $\begin{array}{l}\text { Nominal total } \\
\text { load, lbs }\end{array}$ & 550 & -550 & -250 & -100 & 450 & 450 \\
\hline $\begin{array}{l}\text { Total No. of } \\
\text { cycles tested }\end{array}$ & 36 & 33 & 38 & 46 & 33 & 25 \\
\hline $\begin{array}{l}\text { Ratcheting rate } \\
\text { per cycle), \% }\end{array}$ & 0.0014 & -0.0019 & -0.003 & -0.008 & 0.03 & 0.002 \\
\hline $\begin{array}{l}\text { Initial stress on } \\
\text { Bar 1, MPa }\end{array}$ & -61.8 & -75.4 & -113.7 & -135.2 & -90.9 & -4.3 \\
\hline $\begin{array}{l}\text { Initial stress on } \\
\text { Bar 2, MPa }\end{array}$ & 141.3 & -1.9 & 78.0 & 119.5 & 155.3 & 6.0 \\
\hline $\begin{array}{l}\text { Initial residual } \\
\text { total strain, \% }\end{array}$ & 0.33 & 0.29 & 0.27 & 0.13 & -0.25 & 0 \\
\hline $\begin{array}{l}\text { Reference cycle } \\
\text { No. }\end{array}$ & 6 & 6 & 6 & 6 & 6 & $283.1 \pm 1.9$ \\
\hline $\begin{array}{l}\text { Min. total strain } \\
\text { of the reference } \\
\text { cycle, \% }\end{array}$ & 0.4 & 0.32 & 0.23 & 0.047 & 0.11 & 0.076 \\
\hline $\begin{array}{l}\text { Stress range per } \\
\text { cycle for Bar 1, } \\
\text { MPa }\end{array}$ & $210.3 \pm 0.9$ & $206.9 \pm 1.1$ & $266.8 \pm 1.1$ & $299.8 \pm 1.0$ & $292.5 \pm 1.1$ & $287.6 \pm 1.7$ \\
\hline $\begin{array}{l}\text { Stress range per } \\
\text { cycle for Bar 2, } \\
\text { MPa }\end{array}$ & $206.5 \pm 1.1$ & $202.6 \pm 1.0$ & $262.8 \pm 0.9$ & $297 \pm 0.8$ & $289.9 \pm 0.8$ & 2 \\
\hline
\end{tabular}

Shown below in Fig. 16 is the envelope of loading conditions that pass the EPP strain limits code case (ASME B\&PV Code Case N-861). The ordinate is the time delay in minutes as defined in Fig. 7 and the abscissa is the total applied load for the two bars with 0.25 in diameter. The analytic boundaries shown in red and blue are incremental solutions to this two-bar problem using the strain limits code case procedure. The red boundary is determined from incremental changes in the applied total load that reduce ratcheting and the blue boundary is determined from incremental changes in the applied load from inside the nonratcheting regime that show no ratchet. The difference is due to the size of the incremental change in applied load. Also shown in Fig. 16 are the locations of the experiment test point coordinates. The circled red cross points are those that did not pass the 1\% strain limits criteria and the circled green smile points are those that did.

Shown in Table 8 are the measured strain accumulations for the various test points identified in Fig. 16. There are no measured strains greater than $1 \%$ that fall within the analytically-determined strain limits boundary determined from the EPP analysis (Wang, et. al., 2017b). There are experimental points that fall outside the EPP boundary, thus indicating their conservatism. But, generally, it is shown that for points 
farther outside the boundary, the strain limits are not satisfied, thus indicating that the EPP boundary is not over-conservative.

As stated above, incorporation of the SMT data-based approach for creep-fatigue damage evaluation into the EPP methodology will avoid the use of the " $D$ " diagram and minimize over-conservatism while properly accounting for localized defects and stress risers. The plan is to use the strain range results from the EPP strain limits procedure as input to the strain range based SMT design curve. The two-bar test results can also be used to address the validity of this approach. The strain ranges of interest are those that first satisfy the EPP strain limits code case. From Fig. 16 and Table 8 the applicable strain ranges are those at a $3 \mathrm{~min}$ delay time at -250 and $550 \mathrm{lb}$. load and a $10 \mathrm{~min}$ delay and 50, 150 and $300 \mathrm{lb}$ load.

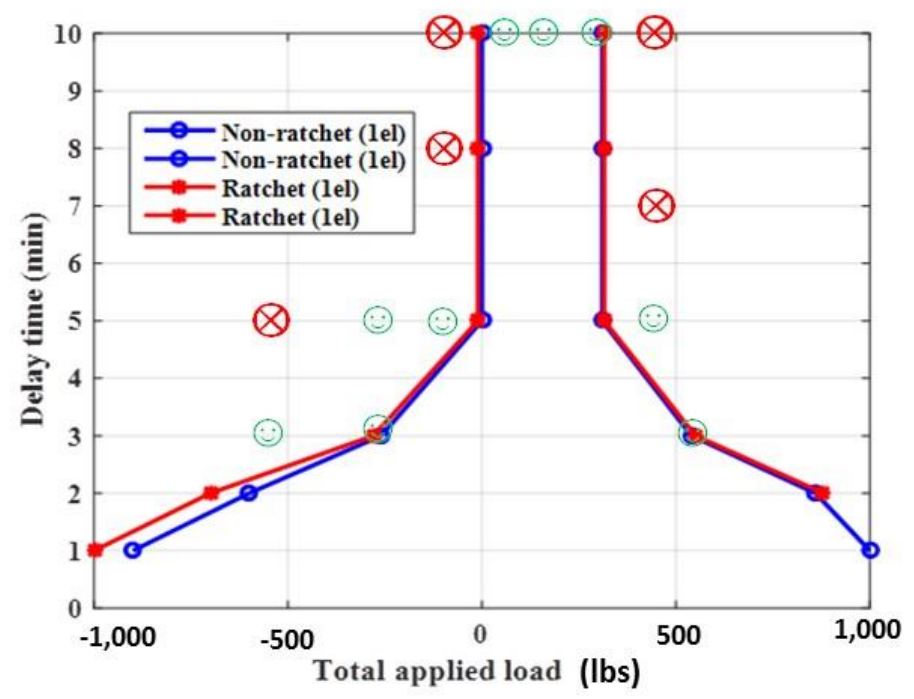

Fig. 16. EPP Strain limits envelope and test data for $405^{\circ} \mathrm{C}$ to $705^{\circ} \mathrm{C}$ temperature range (the green symbol $\odot$ passed $1 \%$ strain limits, while the red symbol $\otimes$ did not pass $1 \%$ strain limits).

Table 9 is a comparison of the experimentally measured strain range for these loading conditions to the corresponding analytically determined strain ranges from the EPP strain limits evaluation. Fig. 17 to Fig. 21 show side-by-side comparisons of the experimental and analytical hysteresis loops for Bar 1 and Bar 2. The numerical hysteresis loops are from EPP simulations of the system using 1D bar elements to represent deformation in each bar. The elastic and thermal expansion properties of the bars match those in ASME Sec. II, Part D. The temperature-dependent perfectly plastic yield stress is computed using the procedure for finding the pseudo-yield stress detailed in the EPP strain limits code case (ASME B\&PV Code Case N-861). For the cases presented in the figures the system achieves plastic shakedown so a single, stable loop summarizes the steady-state system response.

As seen from Table 4, for the three cases at 10min delay, the analytic strain range is greater than the experimental range for Bar 2, the thermal lagging bar with the largest strain range. The margin is conservative but not excessive. Conversely, the experimental strain range in Bar 1, the thermal leading bar with the lower strain range, is larger than the analytic strain range, which is unconservative. 
Table 8. Experimental results for $405^{\circ} \mathrm{C}$ to $705^{\circ} \mathrm{C}$ temperature range.

\begin{tabular}{c|c|c|c}
\hline Nominal total load (lbs) & Time delay (min) & $\begin{array}{c}\text { Ratcheting strain } \\
\text { in 200 hr, \% }\end{array}$ & $\begin{array}{c}\text { Pass/fail 1\% } \\
\text { strain limits }\end{array}$ \\
\hline-550 & 3 & $0.20 \%$ & Pass \\
\hline-550 & 5 & $-8.79 \%$ & Fail \\
\hline-250 & 3 & $-0.07 \%$ & Pass \\
\hline-250 & 5 & $-0.47 \%$ & Pass \\
\hline-100 & 5 & $-0.19 \%$ & Pass \\
\hline-100 & 10 & $-2.31 \%$ & Fail \\
\hline-100 & 8 & $-1.15 \%$ & Fail \\
\hline 50 & 10 & $-0.56 \%$ & Pass \\
\hline 150 & 10 & $-0.08 \%$ & Pass \\
\hline 300 & 10 & $0.47 \%$ & Pass \\
\hline 450 & 10 & $5.19 \%$ & Fail \\
\hline 450 & 7 & $4.18 \%$ & Fail \\
\hline 450 & 5 & $0.29 \%$ & Pass \\
\hline 550 & 3 & $0.20 \%$ & pass \\
\hline
\end{tabular}

For the two cases with lower strain ranges as a result of the lower delay time, the analytic strain range is slightly non-conservative in Bar 2 and more non-conservative in Bar 1. Interestingly, the experimental data show that Bar 2 had larger mechanical strain ranges while loaded at higher thermal stress with 10 min time delay, it showed smaller strain ranges than Bar 1, while at the lower loaded 3 min delay, Bar 1 experiences the greater strain range than Bar 2.

Table 9. Experimental and analytical strain ranges.

\begin{tabular}{c|c|c|c|c|c}
\hline \multirow{2}{*}{$\begin{array}{c}\text { Nominal Total } \\
\text { Load, (lbs) }\end{array}$} & $\begin{array}{c}\text { Delay time, } \\
(\mathrm{min})\end{array}$ & \multicolumn{2}{|c|}{$\begin{array}{c}\text { Mechanical strain range Bar 1 } \\
(\%)\end{array}$} & \multicolumn{2}{c}{$\begin{array}{c}\text { Mechanical strain range -Bar 2 } \\
(\%)\end{array}$} \\
\cline { 3 - 6 } & & Exp. & Anal. & Exp. & Anal. \\
\hline-250 & 3 & 0.17 & 0.096 & 0.11 & 0.099 \\
\hline 550 & 3 & 0.17 & 0.0982 & 0.11 & 0.099 \\
\hline 50 & 10 & 0.32 & 0.183 & 0.41 & 0.49 \\
\hline 150 & 10 & 0.30 & 0.183 & 0.41 & 0.49 \\
\hline 300 & 10 & 0.30 & 0.184 & 0.42 & 0.493 \\
\hline
\end{tabular}

The side-by-side plots of the hysteresis loops in Fig. 17 through Fig. 21 show good qualitative agreement between experiment and analysis. The plots on the experimental data consist of five consecutive cycles (from cycle number 10 to cycle number 14) for each condition and the plots from EPP analysis consist of first 9 to 10 cycles. Among these test conditions, for the more highly loaded cases at 10min delay, the plasticity in the Bar 2 hysteresis loops qualitatively show good agreement with the experimental loops. The experiment loops in Bar 1 show slight inelasticity, closely approximating the elastic behavior from the analysis. For the more lightly loaded 3 min delay cases, both the experimental and analytic loops in both bars show elastic behavior; although, there was an as yet unexplained kink in the Bar 2 response. (Wang, et. al., 2017b).) 
Although the hysteresis loops are compatible and the agreement between experiment and analysis is not unreasonably conservative for the higher load cases and larger strain ranges, the non-conservatism at lower loads and strain ranges warrants additional investigation.

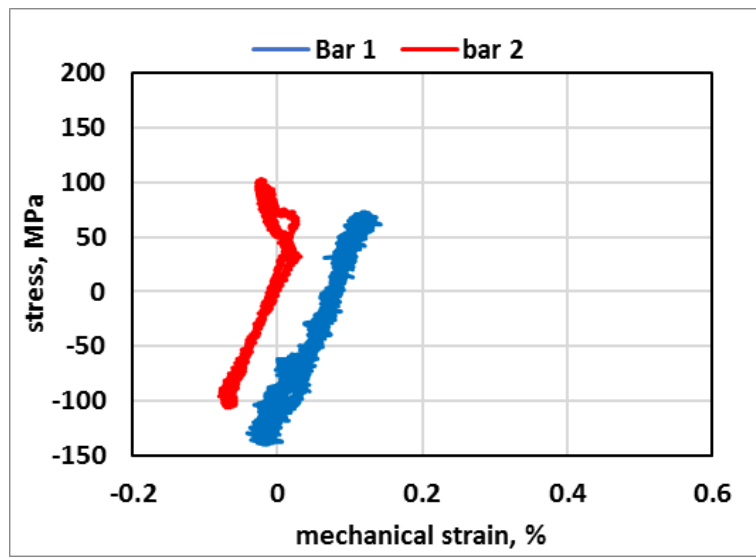

Two-bar Experiment

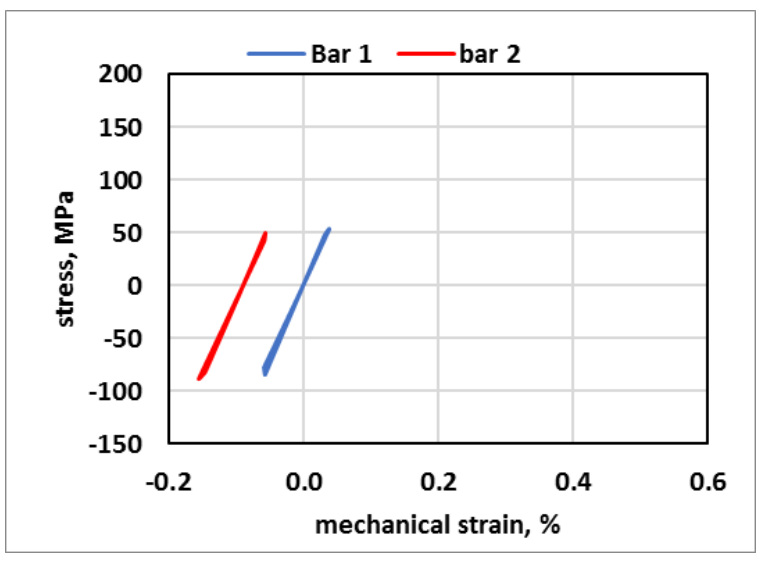

EPP analysis

Fig. 17. Hysteresis loops of the two bars with $-250 \mathrm{lb}$ and 3 min delay loading condition.

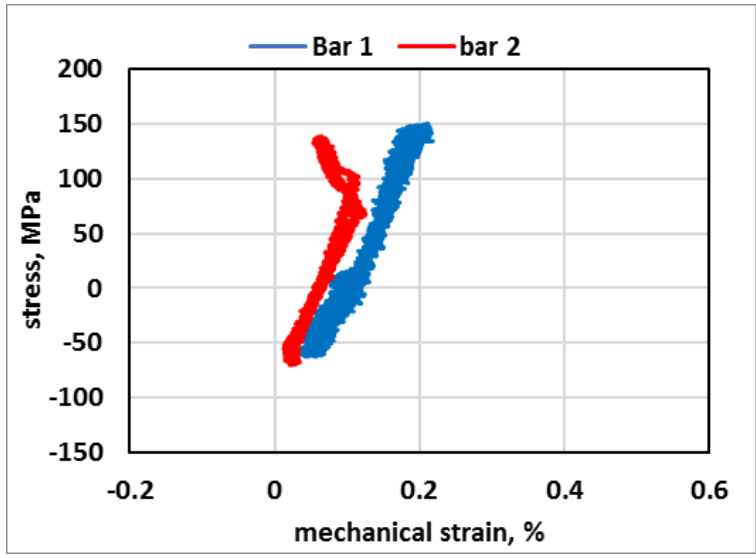

Two-bar Experiment

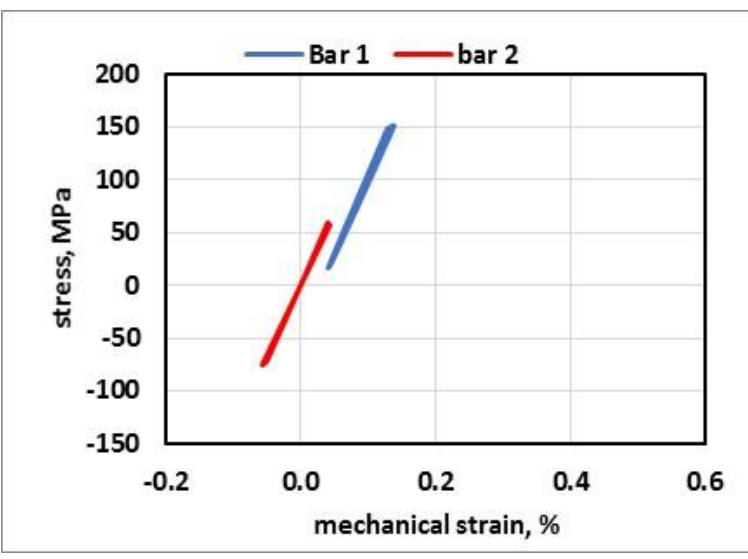

EPP analysis

Fig. 18. Hysteresis loops of the two bars with $550 \mathrm{lb}$ and 3 min delay loading condition. 


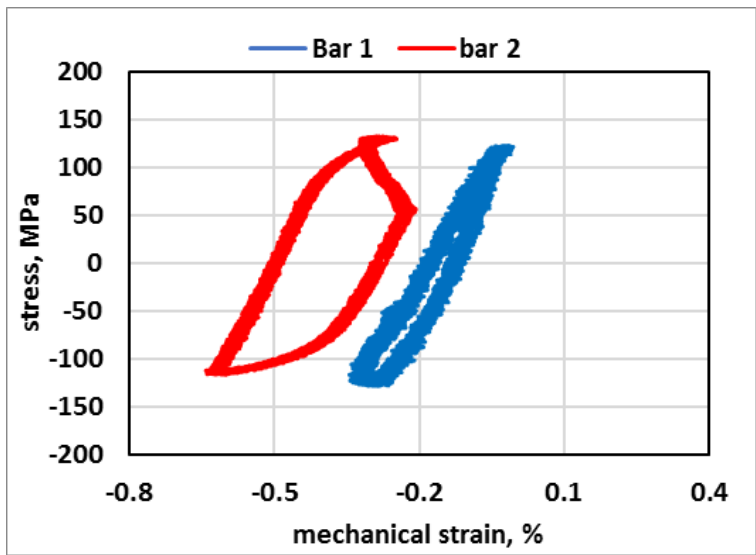

Two-bar Experiment

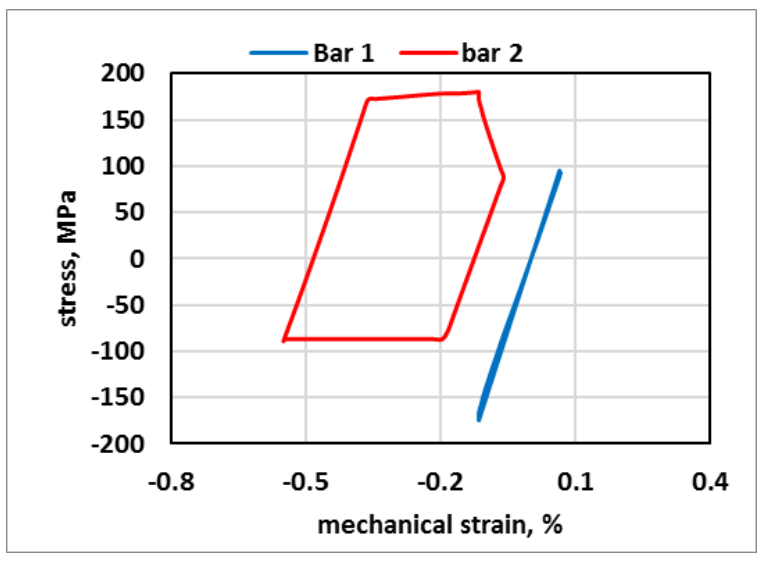

EPP analysis

Fig. 19. Hysteresis loops of the two bars with $50 \mathrm{lb}$ and 10 min delay loading condition.

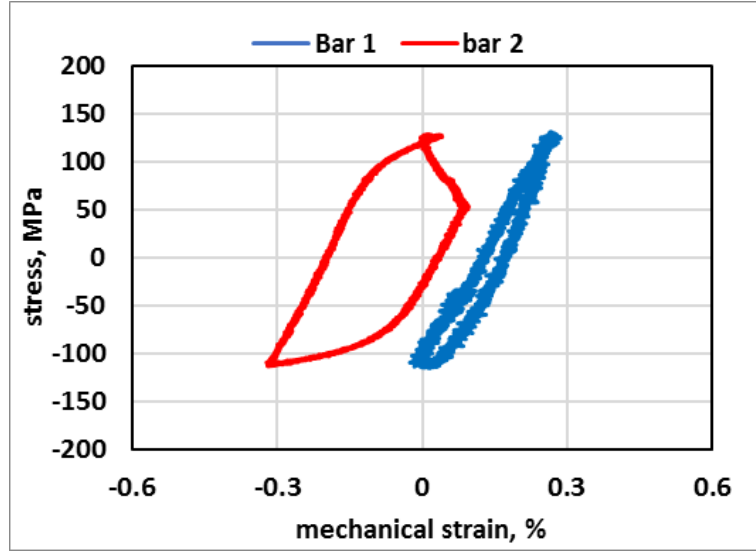

Two-bar Experiment

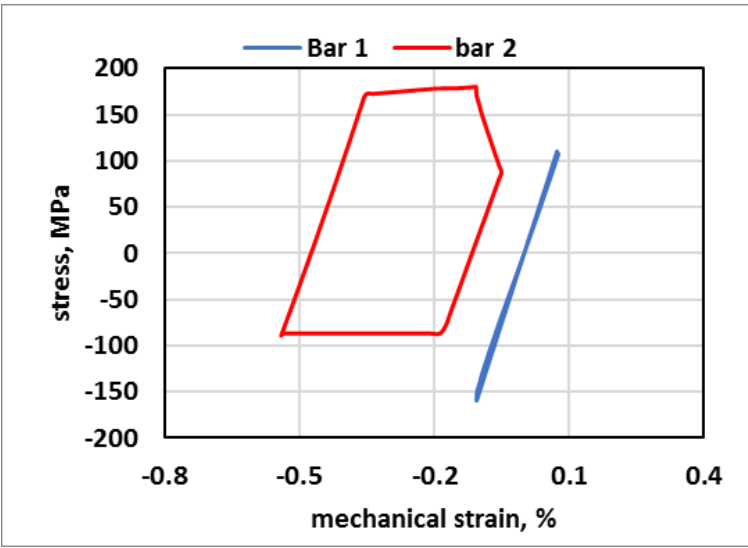

EPP analysis

Fig. 20. Hysteresis loops of the two bars with $150 \mathrm{lb}$ and 10 min delay loading condition.

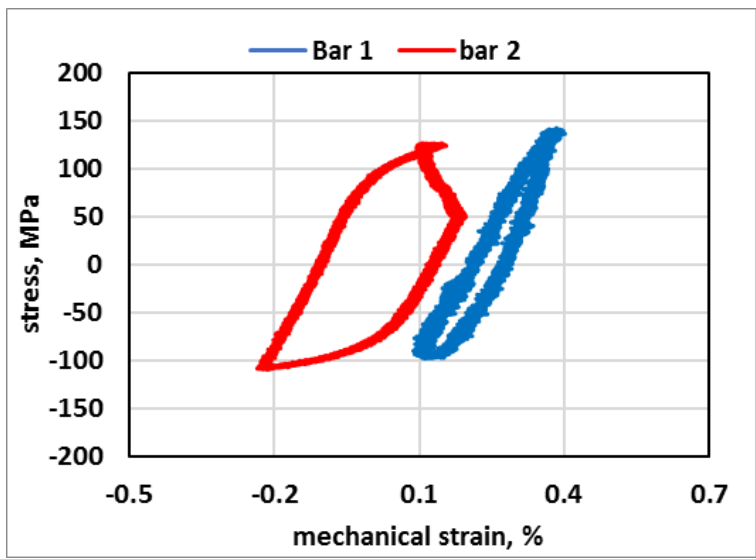

Two-bar Experiment

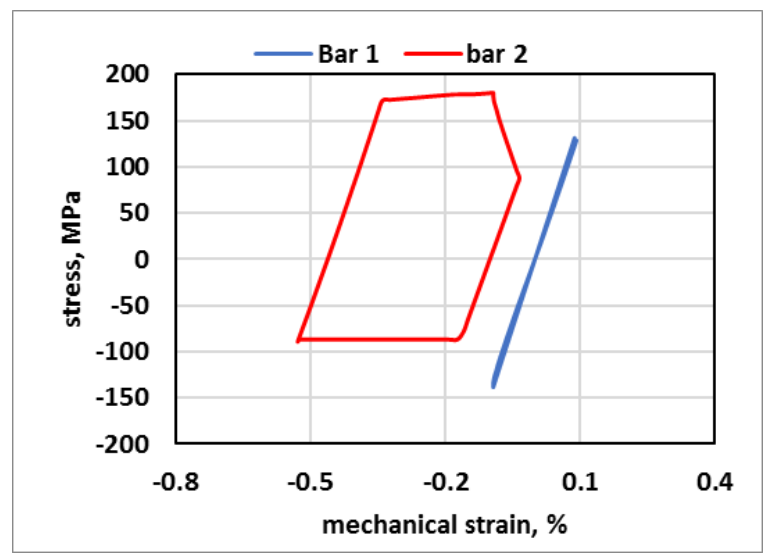

EPP analysis

Fig. 21. Hysteresis loops of the two bars with $300 \mathrm{lb}$ and 10 min delay loading condition. 


\section{SUMMARY}

The development of the integrated EPP combined SMT creep-fatigue damage evaluation approach is reported. The goal of the proposed approach is to combine the advantage of the EPP strain limits methodology that avoids stress classification with the advantage of the SMT method for evaluating creepfatigue damage without deconstructing the cyclic history into separate fatigue and creep damage evaluations. In support of the development of this methodology in FY17, experiments were performed on Alloy 617 with longer tension hold times of $30 \mathrm{~min}$ and $10 \mathrm{hr}$ at $950{ }^{\circ} \mathrm{C}$. The enhanced damage resulting from strain redistribution and slowed stress relaxation due to follow up effects was demonstrated in the test results. Although standard strain controlled creep-fatigue on smooth bar showed saturation at $180 \mathrm{~s}$ hold time, the SMT test with 30 min hold time did not show saturation. The test with hold time of $10 \mathrm{hr}$ showed a reduction of creep-fatigue cycles by $67 \%$ when compared to the test with $10 \mathrm{~min}$ hold time.

Pressurized SMT specimens on Alloy 617 were used to assess the role of sustained primary loading on cyclic life. Although high pressures reduced cyclic life, it was shown that such high pressure levels would not be permissible under normal design limitations on pressure as a function of service life.

Two-bar thermal ratcheting tests were conducted on $316 \mathrm{H}$ stainless steel specimens with an applied temperature transient from 405 to $705^{\circ} \mathrm{C}$ at several constant applied combined total loads. These test data points were then evaluated analytically using the EPP strain limits procedures and compared to the $1 \%$ EPP strain limits boundary. There were no measured strains greater than $1 \%$ that fell within the analytically determined strain limits boundary. Although there were experimental points that fell outside the EPP boundary, generally, it was shown that the EPP boundary was not over-conservative. Regarding the strain range assessment, the experimental and analytic hysteresis loops were qualitatively compatible. The agreement between experimental and analytical strain ranges is not unreasonably conservative for the higher load cases and larger strain ranges, but non-conservatism at lower loads and strain ranges warrants additional investigation. 


\section{REFERENCES}

ASME B\&PV Code Case N-861 "Satisfaction of Strain Limits for Division 5 Class A Components at Elevated Temperature Service Using Elastic-Perfectly Plastic Analysis”.

ASME B\&PV Code Case N-862 "Calculation of Creep-Fatigue for Division 5 Class A Components at Elevated Temperature Service Using Elastic-Perfectly Plastic Analysis Section III, Division 5"

Carroll, L. J., Cabet, C., R. Madland and Wright, R. N., (2011). "Creep and Environmental Effects on the High Temperature Creep-fatigue Behavior of Alloy 617," Journal of ASTM International, Vol. 8, No. 6, pp. 1-13, https://doi.org/10.1520/JAI103797.

Swindeman, R., Robinson, D., Williams, B. and Thomas, D., (1982), “Two-Bar Thermal Ratcheting Experiments on 21/4Cr-1Mo Steel," Technical Report No. ORNL/TM-8001, Oak Ridge National Laboratory, Oak Ridge, TN.

Wang, Y., Sham, T.-L, and Jetter, R. I., (2013a), "Progress report on the development of test procedure for the two-bar thermal ratcheting experiment for Alloy 617”, ORNL/TM-2013/318, Oak Ridge National Laboratory, Oak Ridge, TN.

Wang, Y., Jetter, R. I., Krishnan, K., and Sham, T.-L, (2013b) "Progress Report on Creep-Fatigue Design Method Development Based on SMT Approach for Alloy 617”, ORNL/TM-2013/349, Oak Ridge National Laboratory, Oak Ridge, TN.

Wang, Y., Jetter, R. I. and Sham, T.-L, (2014), “Application of Combined Sustained and Cyclic Loading Test Results to Alloy 617 Elevated Temperature Design Criteria”, ORNL/TM-2014/294, Oak Ridge National Laboratory, Oak Ridge, TN.

Wang, Y., Jetter, R. I., Baird, S. T., Pu, C. and Sham, T.-L., (2015), "Report on FY15 Two-Bar Thermal Ratcheting Test Results", ORNL/TM-2015/284, Oak Ridge National Laboratory, Oak Ridge, TN.

Wang, Y., Jetter, R. I., and Sham, T.-L., (2016), "Preliminary Test Results in Support of Integrated EPP and SMT Design Methods Development", ORNL/TM-2016/76, Oak Ridge National Laboratory, Oak Ridge, TN.

Wang, Y., Jetter, and Sham, T.-L., (2017a), "Pressurized Creep-Fatigue Testing of Alloy 617 Using Simplified Model Test Method", Proceedings of the ASME 2017 Pressure Vessels and Piping Conference, PVP2017-65457

Wang, Y., Jetter, R. I., Messner, M., Mohanty , S., and Sham, T.-L., (2017b), “Combined Load and Displacement Controlled Testing to Support Development of Simplified Component Design Rules for Elevated Temperature Service", Proceedings of the ASME 2017 Pressure Vessels and Piping Conference, PVP2017-65455 
ORNL/TM-2017/351

\section{ELECTRONIC DISTRIBUTION}

\begin{tabular}{ll} 
Name & Affiliation \\
Corwin, W. & DOE-NE \\
Gougar, H. & INL \\
Grandy, C. & ANL \\
Hill, R.N. & ANL \\
Jetter, R.I. & R.I. Jetter Consulting \\
Lara-Curzio, E. & ORNL \\
Li, D. & DOE-NE \\
Lin, L. & ORNL \\
McMurtrey, M. & INL \\
Messner, M.C. & ANL \\
Natesan, K. & ANL \\
Qualls, L. & ORNL \\
Robinson, B. & DOE-NE \\
Sham, T.-L. & ANL \\
Wang, H. & ORNL \\
Wang, Y. & ORNL \\
Wright, R.N. & INL \\
Yankeelov, J. & DOE-ID \\
\hline
\end{tabular}

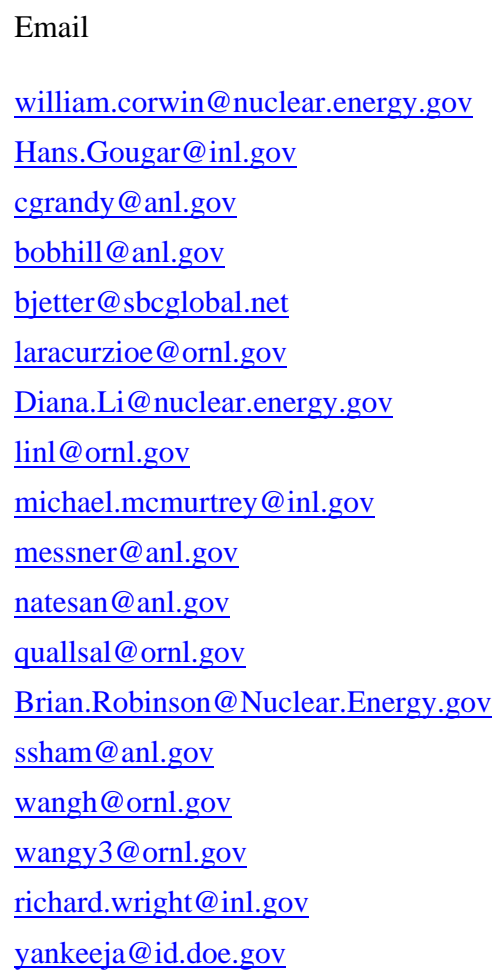

